\title{
Micro-saw devices based on randomly-oriented PZT films: Design, fabrication and characterization
}

Jonathan Taub

Follow this and additional works at: https://researchrepository.wvu.edu/etd

\section{Recommended Citation}

Taub, Jonathan, "Micro-saw devices based on randomly-oriented PZT films: Design, fabrication and characterization" (2015). Graduate Theses, Dissertations, and Problem Reports. 6777.

https://researchrepository.wvu.edu/etd/6777

This Thesis is protected by copyright and/or related rights. It has been brought to you by the The Research Repository @ WVU with permission from the rights-holder(s). You are free to use this Thesis in any way that is permitted by the copyright and related rights legislation that applies to your use. For other uses you must obtain permission from the rights-holder(s) directly, unless additional rights are indicated by a Creative Commons license in the record and/ or on the work itself. This Thesis has been accepted for inclusion in WVU Graduate Theses, Dissertations, and Problem Reports collection by an authorized administrator of The Research Repository @ WVU. For more information, please contact researchrepository@mail.wvu.edu. 


\title{
Micro-saw devices based on randomly- oriented PZT films: design, fabrication and characterization.
}

\author{
Jonathan Taub
}

Thesis submitted to the Benjamin M. Statler College of Engineering and Mineral Resources at West Virginia University in partial fulfillment of the requirements for the degree of

\section{Master of Science}

in

\section{Mechanical Engineering}

Thomas Evans, $\mathrm{PhD}$

Mark A. Jerabek, PhD

Edward M. Sabolsky, Ph.D., Chairperson and Advisor

Konstantinos Sierros, $\mathrm{PhD}$

Department of Mechanical and Aerospace Engineering

Morgantown, West Virginia

2015

Keywords: PZT, SAW, Thin film, Sol-gel

Copyright 2015 Jonathan Taub 


\section{ABSTRACT}

The main objective of this work was to research and develop a sensor device to monitor gas leakage in cryogenic temperatures and high vacuum. In addition, the sensor device should be small in size, function with low power, and display a short recovery time. The end application for this technology would be to monitor fuel leaks of hydrazine when refueling space satellites. To meet the specified requirements, an acoustic wave device was studied in this work. A micro-surface acoustic wave $(\mu \mathrm{SAW})$ device was fabricated through a multi-layer thin film technique, where the active sensing material is based on a $300 \mathrm{~nm}$ thick $\mathrm{PbZr}_{0.52} \mathrm{Ti}_{0.48} \mathrm{O}_{3}$ (PZT) piezoelectric film grown via a sol-gel process. The electrodes were based on $\mathrm{Si} / \mathrm{SiO}_{2} / \mathrm{TiO}_{\mathrm{x}} / \mathrm{Pt}$ and $\mathrm{Si} / \mathrm{SiO} 2 / \mathrm{TiO}_{\mathrm{x}}$ multi-layered structures and were fabricated by thermal oxidation and sputtering techniques. Improved deposition and crystallization methods for the PZT film were developed in this work which resulted in crack- and porous-free texturized and randomly-oriented PZT films. The phase, chemistry and microstructure of the PZT films were determined by X-ray diffraction (XRD), Energy Dispersive X-Ray Analysis (EDX), Scanning Electron Microscopy (SEM) and Atomic Force Microscopy (AFM) techniques. The surface energy of the films was measured by means of a static sessile drop method. The ferroelectric and electrical characterization of the film was completed longitudinally by measuring the polarization-voltage (P-V), capacitance-voltage (C-V) and current-voltage (I-V) curves. The propagation wave velocity for the multi-layered structure was approximated using an electromechanical equivalent model and the results were used to design the interdigitated

transducers (IDTs) for the SAW devices. IDTs were later deposited over the PZT via photolithography process. Finally, the electro-acoustic frequency response in $|\mathrm{S} 21|$ mode was 
measured using a vector network analyzer (VNA) and Rayleigh mode SAW and non-Rayleigh mode SAW responses were observed. 


\section{ACKNOWLEDGMENT}

I would like to thank Dr. Sabolsky for giving me the opportunity to conduct research and advising me and supporting me during the entire process of the presented work.

I acknowledge the usage of the WVU Shared Research Facilities during the fabrication and part of the characterization of the devices and want to thanks Dr. K. Brown, Dr. W. Ding, H. Hart and Dr. M. Redigolo for their help and advice, great predisposition, very helpful discussions and great sense of humor that made the long days at the cleanroom much better.

I would like to acknowledge the generous support of NASA Goddard Space Flight Center Satellite Servicing Capabilities Office (SSCO) under Grant NNX10D17A and Contract NNG10CR16C that made this work possible. I would like to thank Dr. Evans for allowing me to participate in this project and always making sure that everything that was needed would be available. I also want to thank Lindsay Carter for helping me getting all the things that were required and doing so with such a great predisposition.

I also thank Dr. D. Lederman, Dr. K. Sierros and Dr. D. Korakakis for allowing the usage of lab equipment, Dr. T. Johnson for teaching me how to do the ferroelectric measurements, Dr. Jerabek for advising me regarding the usage of the Vector Network Analyzer and being available spend time discussing it and to Kathy Sabolsky for helping and teaching me to work around the lab when I first came to the University. 
I would like to thank lab mates that made the long hours in the lab and the office much more enjoyable: Lisa, Tomas, Tim, Borja, Ozcan, Ruddy, Jonathan, Patrick, Raji, Gunes, Josh, Phil, Chad and Sodith.

Finally I would like to thank my family for their support from the distance. 


\section{OUTLINE}

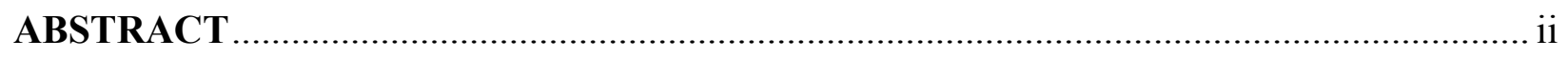

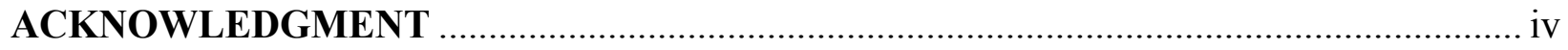

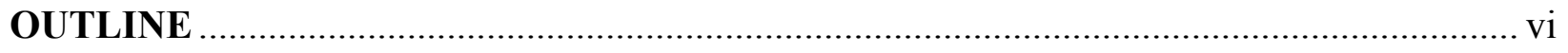

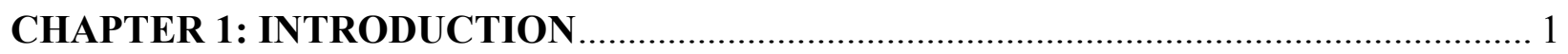

1.1 POWER REQUIREMENTS AND SPACE ENVIRONMENT CONDITIONS ............. 1

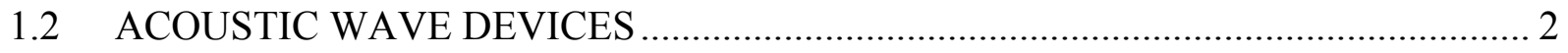

1.3 PIEZOLECTRIC MATERIALS FOR SAW DEVICES ……………………............. 10

1.2.1 Bulk and film piezoelectric materials ...................................................................... 10

1.2.2 PZT Film as a piezoelectric film for SAW devices.................................................. 12

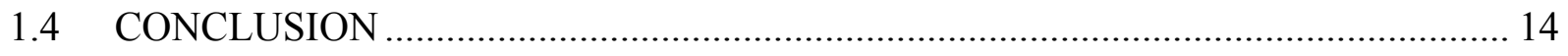

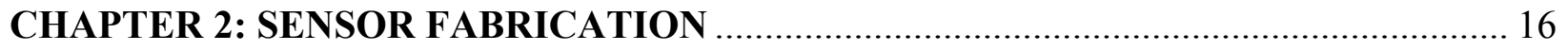

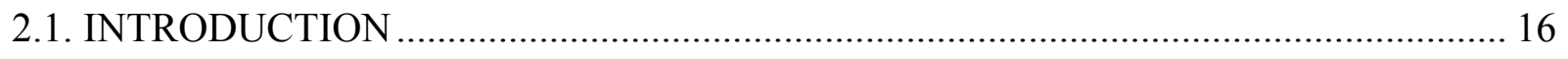

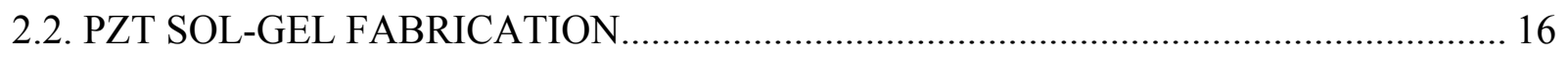

2.3 FABRICATION OF THE SUBSTRATE AND $\mu$ DEVICE ……………………….......... 20

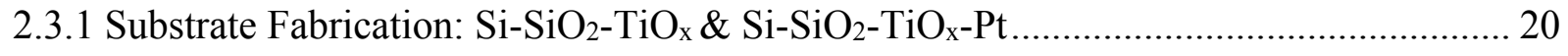

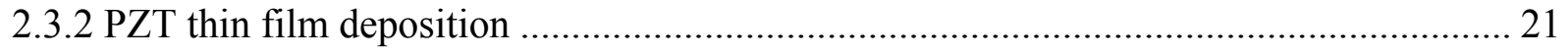

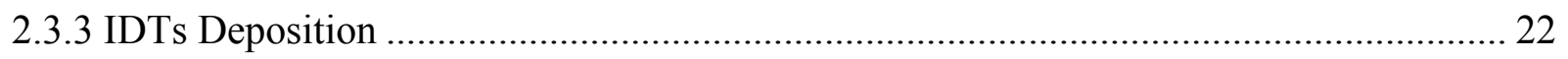

2.4 CHALLENGES AND RESOLUTION ENCOUNTERED DURING FABRICATION ... 23 
2.4.1 Film porosity

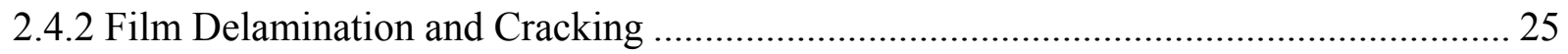

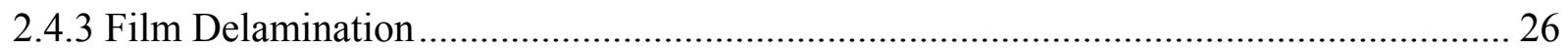

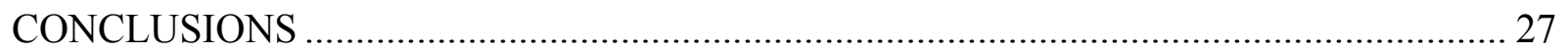

CHAPTER 3: ACTIVE LAYER CHARACTERIZATION: A COMPARATIVE STUDY OF

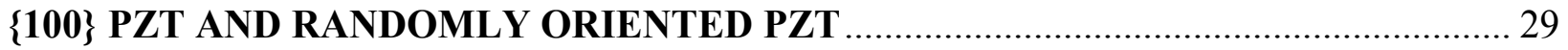

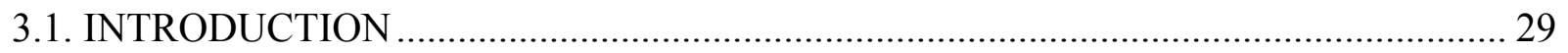

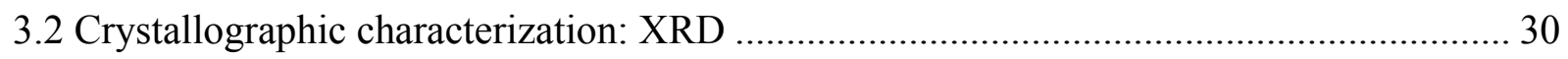

3.3 Microstructural Characterization: Atomic Force Microscope (AFM) ……………............ 32

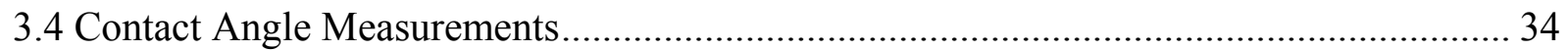

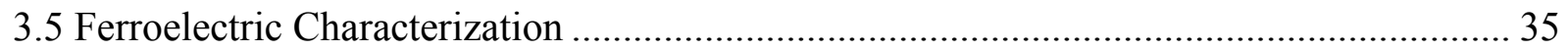

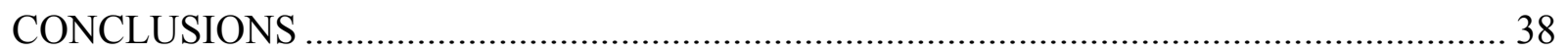

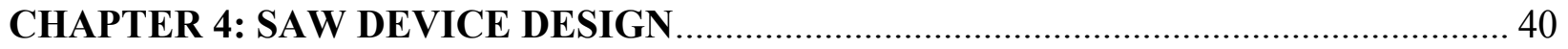

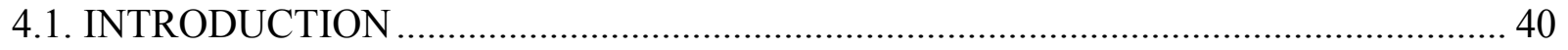

4.2 PROPAGATION WAVE VELOCITY MODELING ....................................................... 42

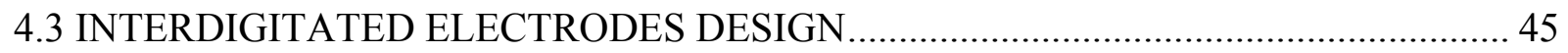

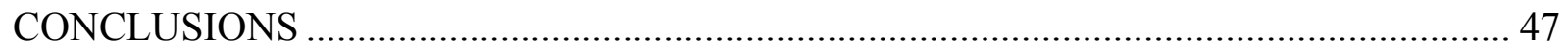

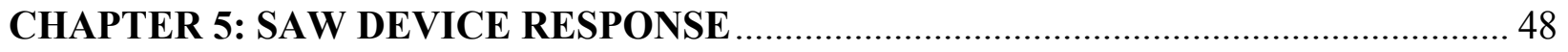

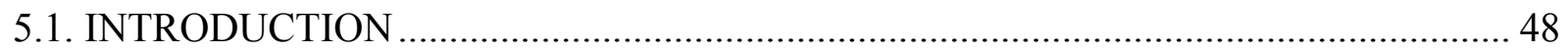


5.2 FREQUENCY RESPONSE OF SAW DEVICES BASED ON RANDOMLY ORIENTED

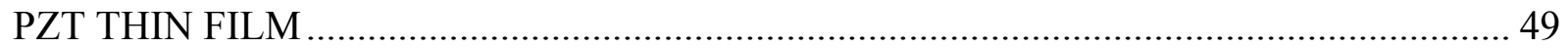

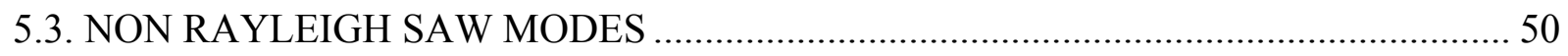

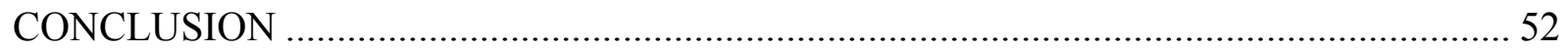

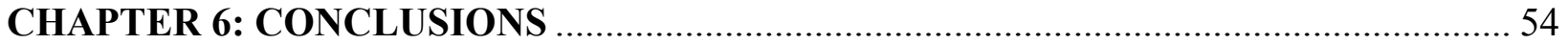

FUTURE WORK

REFERENCES 


\section{CHAPTER 1 INTRODUCTION}

\subsection{POWER REQUIREMENTS AND SPACE ENVIRONMENT CONDITIONS}

The motivation for this study was to develop a device for gas leakages detection in the geostationary orbit. The environmental conditions the device would encounter influenced the decision-making process for selecting the device and its specific materials.

A device placed in geo-stationary orbit will be subject to ambient conditions that reach cryogenic temperatures of $-120^{\circ} \mathrm{C}$ and could suffer cycles of temperatures from $120^{\circ} \mathrm{C}$ to $150^{\circ} \mathrm{C}$ due to the direct impact of the Sun's radiation. Additionally, the device would be impacted by an extremely low environmental pressure of $1 \times 10^{-9}$ Torr. The integrity of a device subject to this environment could be compromised due to numerous factors: fatigue effects resulting from temperature cycles; degassing of specific materials from low vacuum conditions; and structural instability of the device and ductile-brittle transformations that could make the device more vulnerable to damages. Consideration must also be given to issues with functional materials, due to the possible impoverishment of specific properties pursuant to these extreme conditions (such as electrical, thermal, mechanical, magnetic, and ferroelectric properties). 
One must also consider radiation hazards in addition to ambient environmental conditions. These include energetic electrons, Galactic Cosmic Radiation (GCR), and Solar Particle Events (SPEs). [1] [2]Internal charging can occur due to the high energy electrons that penetrate the materials, and significant surface charging $(\mathrm{kV})$ can occur due to present low energy electrons. These effects should be anticipated when designing a device for space applications, since a protective shield might be required to ensure sustained integrity and functioning.

In addition to material selection, specific requirements were also given which included low power consumption, small data processing, reduced size, low weight, and high sensitivity.

\subsection{ACOUSTIC WAVE DEVICES}

Acoustic-wave sensors work by combining a traveling wave with a confinement structure to produce a standing wave with a characteristic frequency determined by the propagating velocity of the traveling wave and the dimensions of the confinement structure. The detection of the measurand will occur due to the interaction of it with the devices which will modify the propagating velocity or the confinement dimensions and consequently the characteristic frequency of the device [3]. The most commonly use configurations includes the thickness share mode (TSM) resonator, the acoustic plate mode (APM) device, the surface acoustic wave (SAW) device, the flexural plate wave (FPW) device and the love wave (LV) device. The choice of the device to use will depend on the application that they will be used for and the restrictions that might exist such as sensitivity, mechanical strength, ability to immerse, frequency range and size among others. The devices previously mentioned are described next. 


\section{Thickness Shear Mode (TSM) resonator}

The TSM, also known as the quartz crystal microbalance (QCM) is the oldest wave resonator in which an AT-cut Quartz disk is patterned with parallel circular electrodes on both sides. Figure 1.1 shows an image of a typical design for this device. When a voltage is applied between these electrodes a shear deformation of the crystal is produced. When an alternating voltage is applied between the electrodes oscillation will occur creating bulk acoustic waves (BAW). There will exist a fundamental thickness shear mode resonator that is inversely proportional to the thickness of the crystal. When a mass is uniformly added onto a quartz crystal surface there will be a change in the resonant frequency [4]. This is the principle of operation of this device as a sensor. Among the devices the presented acoustic one has the lowest mass sensitivity. Typically in the fundamental mode the resonance frequencies are around 5 to $30 \mathrm{MHz}$. Nowadays thinner devices with fundamental frequencies up to $150 \mathrm{MHz}$ are available. These thinned devices that produce higher resonance frequencies and then higher sensitivity are on the other hand more fragile and difficult to produce. [3] [5]
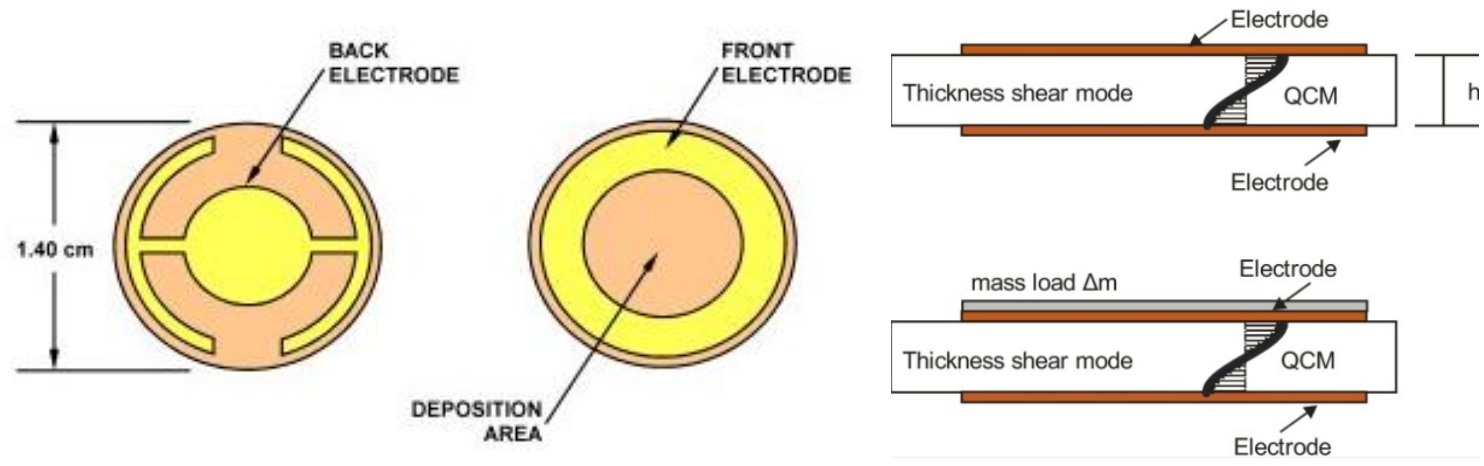

Figure 1.1a Electrode geometry of quartz-crystal samples [4], Figure 1.1b Upper part presents a QCM which resonates in the thickness shear mode. The thickness $h$ of the quartz resonator is crucial for the fundamental resonance frequency. Lower part presents an additional mass load that adheres to the sensor and results in a shift of the resonance frequency. [6] 
Shear Horizontal Acoustic Plate Mode (SH-APM)

SH-APM sensors are typically Quartz crystal based devices that produce shear-horizontal (SH) waves by means of two interdigitated electrodes (IDTs) deposited over one surface of the crystal. SH waves have particle displacement mostly parallel to the plate surface and perpendicular to the propagation direction along the separation path between the two IDTs. A thin piezoelectric substrate is typically used that works as an acoustic waveguide that confines the energy between the upper and lower surfaces of the plate. For this reason both surfaces experience displacement and then the detection can occur on both sides as a change in resonant frequency due to mass loading. Figure 1.2 present the typical structure of an APM sensor. Typical operation frequencies of SH-APM sensors are 20-200 MHz. [3] [5].

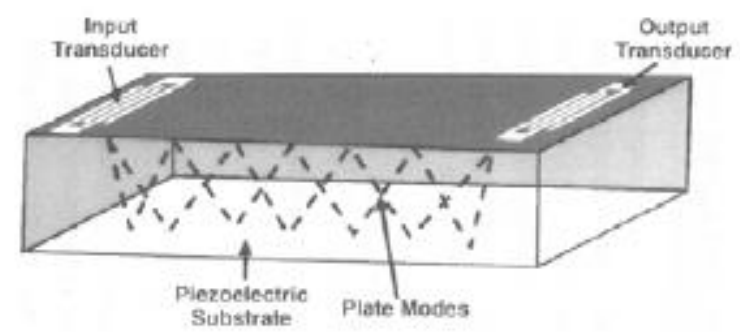

Figure 1.2 Structure of an APM sensor [5]

SH-APM is more sensitive to mass loading than the TSM resonator but less sensitive than SAW sensors. This is because the energy of the wave is not contained on the surface of the crystal but distributed along the thickness. Since the sensitivity is dependent on the thickness of the substrate there will be limitation on the sensitivity due to manufacturing limitations as well. [5]

\section{Surface Acoustic Wave (SAW) device}

The basic surface acoustic wave device consists of a piezoelectric substrate, an input IDT and an output IDT deposited on top of the surface of the piezoelectric material as it is represented in 
Figure $1.3 \mathrm{a} / \mathrm{b}$. When a sinusoidal electrical signal is applied to the input IDT at a specific frequency, an alternating electric field will be generated and then regions of compressive and tensile strain between the fingers of the IDT will be produced. The effect of this will be the creation of a propagating wave in both directions from the IDT. Half of the energy of the waveform will reach the output IDT where the signal will be transform from mechanical to electrical signal. The characteristic frequency at which the acoustic wave is generated it is called the synchronous frequency and will be dependent on the propagation velocity as well as the IDTs designs. The equation 1.1 presents the connection between the synchronous frequency ( $\left.\mathrm{f}_{0}\right)$, the wavelength $(\lambda)$, the velocity of the propagating wave (V) and the IDTs finger and gap width (d), assuming that the finger widths and gaps are the same.

$$
f_{0}=\frac{V}{\lambda}=\frac{V}{4 d}
$$

The wave will propagate in what it is called Rayleigh wave mode or zero wave mode. The Rayleigh wave is composed by a longitudinal and a vertical shear component as is represented in figure 1.3d. Since this wave propagates along the surface of the material, the energy of the wave is maximized at the surface and drops off with depth from the surface. The energy of the propagating wave is contained in one wavelength depth under the surface (described in Figure 1.3c). This is the critical characteristic in SAW sensors that makes it very sensitive to different interactions that can occur with the exposed surface where the wave is propagating. Any factor affecting the propagating velocity will change the resonance frequency $f_{0}$ and this will be one of the working mechanisms for detection in a SAW sensor. Equation 2.2 represent how the propagating velocity can vary with changes on the surface mass $(m)$, the surface stiffness $(c)$, the temperature $(T)$, surface conductivity $(\sigma)$ and pressure $(p)$ among others.

$$
\frac{\Delta V}{V_{0}}=\frac{1}{V_{0}}\left[\frac{\partial V}{\partial m} \Delta m+\frac{\partial V}{\partial c} \Delta c+\frac{\partial V}{\partial T} \Delta T+\frac{\partial V}{\partial \sigma} \Delta \sigma+\frac{\partial V}{\partial P} \Delta p\right]
$$




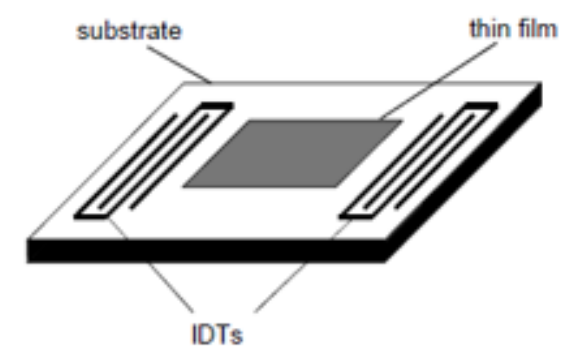

(a)

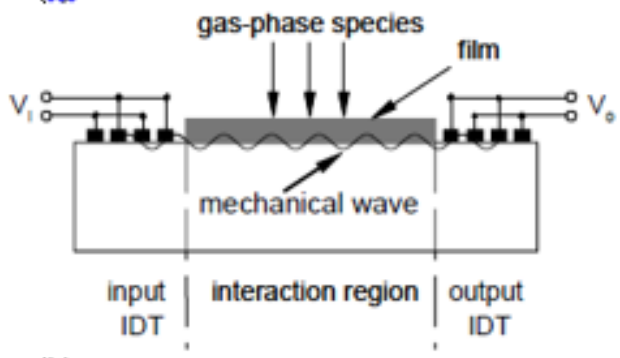

(b) (c)

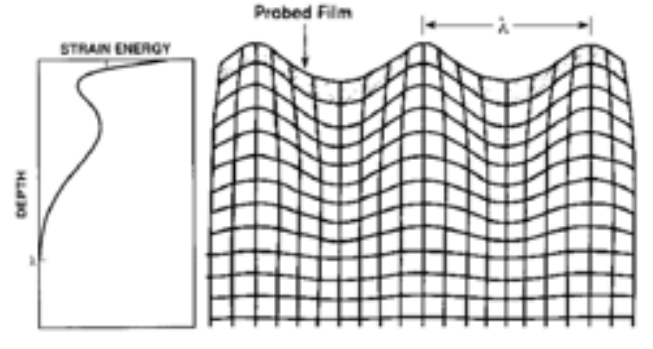

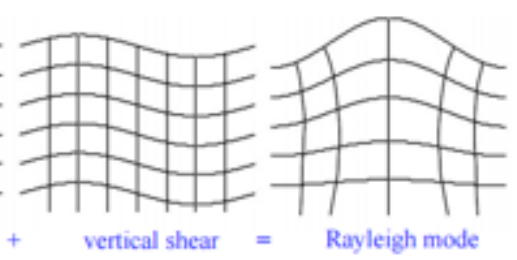

(d)

Figure 1.3 (a) Interdigitated transducer (IDT) configuration as used in SAW sensors [3] (b) Structure of a SAW sensor [3] (c) Curve of strain energy vs depth of the Rayleigh mode wave drop under the surface [7] (d) Composition of a Rayleigh mode wave [8]

When the surface between the IDTs, called a delay line, is coated with specific films, the SAW device can be used for sensing specific species. Table 1.1 presents selected SAW physical sensors for different applications.

Table 1.1 Selected SAW physical Sensors. Data from [8]

\begin{tabular}{|c|c|c|c|c|}
\hline Measurand & Device & Freq. [MHz] & Substrate & Sensitivity \\
\hline Pressure & DL & 90 & $\mathrm{AIN} / \mathrm{Si}$ & $27 \mathrm{ppm} / \mathrm{kPa}$ \\
\hline Force & DL & 8.3 & $\mathrm{LiNbO}_{3}$ & $10.8 \mathrm{ppm} / \mathrm{kN}$ \\
\hline Strain & DL & 10.9 & PZT & $21 \mathrm{ppm} / 10^{-6}$ \\
\hline Position (linear) & DL & 8.3 & $\mathrm{LiNbO}_{3}$ & $120.5 \mathrm{ppm} / \mu \mathrm{m}$ \\
\hline Acceleration & DL & 251 & Quartz & $45 \mathrm{ppm} /\left(\mathrm{m} / \mathrm{s}^{2}\right)$ \\
\hline Flow rate & DL & 73 & $\mathrm{LiNbO}_{3}$ & $204 \mathrm{ppm} /\left(\mathrm{cm}^{3} / \mathrm{s}\right)$ \\
\hline Liquid viscosity & DL & 30 & $\mathrm{LiNbO}_{3}$ & $2.7 \mathrm{ppm} / \mathrm{cP}$ \\
\hline Liquid density & DL & 6 & $\mathrm{ZnO} / \mathrm{Si}_{\mathrm{x}} \mathrm{N}_{\mathrm{y}}$ & $30000 \mathrm{ppm} /\left(\mathrm{g} / \mathrm{cm}^{3}\right)$ \\
\hline Electric field & R & 85 & $\mathrm{Li}_{2} \mathrm{~B}_{4} \hat{\mathrm{O}}_{7}$ & $300 \mathrm{ppm} /(\mathrm{V} / \mu \mathrm{m})$ \\
\hline Voltage & DL & 900 & $\mathrm{LiNbO}_{3}$ & $0.93 \mathrm{ppm} / \mathrm{V}$ \\
\hline Liquid conductivity & DL & 51 & $\mathrm{LiTaO}_{3}$ & $13400 \mathrm{ppm} /(\mathrm{S} / \mathrm{m})$ \\
\hline Magnetic field & DL & 140 & Fe-B/Quartz & $0.38 \mathrm{ppm} /(\mathrm{A} / \mathrm{m})$ \\
\hline Temperature & DL & 43 & $\mathrm{LiNbO}_{3}$ & $92.13 \mathrm{ppm} /{ }^{\circ} \mathrm{C}$ \\
\hline Radiation dose & $\mathrm{R}$ & 199 & Quartz & $0.48 \mathrm{ppm} /(\mathrm{J} / \mathrm{kg})^{0.5}$ \\
\hline Thin film thickness & DL & 75 & $\mathrm{LiNbO}_{3}$ & $9.25 \mathrm{ppm} / \mathrm{nm}$ \\
\hline
\end{tabular}


The SAW devices can be operated at very high frequencies (up to GHz range) which concentrates the surface wave energy close to the surface which increases the surface sensitivity. In principle SAW device could be operated to give mass sensitivities down to the fg $\left(10^{-15} \mathrm{~g}\right)$ level. [8]. The high coupling that exist with media contacting the piezoelectric surface makes them very sensitive to gas but, as their main disadvantage, they cannot be used in liquids since an effect of wave damping due to mass loading is produced.

\section{Flexural Plate Wave (FPW) wave device}

FPW devices have a similar design to that of surface acoustic wave sensors but the IDTs are deposited on top of a diaphragms that has a thickness smaller than the wavelength of the propagating wave. Figure 1.4a presents the typical structure of a FPW device. These devices will have characteristic symmetric and antisymmetric plate modes known as Lamb waves, these modes are presented in figure 1.4b. The particle displacement is similar to that one observed in Rayleigh waves but in contrast the excited wave velocity is smaller than that observed in the SAW devices. The effect that this will have is that for a given wavelength a lower resonance frequency will be excited, which lightens the requirements on the associated electronics. Another interesting property is that when the FPW is dimensioned in a way that the generated wave velocity is lower than in most liquids, then a slow mode of propagation will exist in which there is no radiation from the plate to the liquid and therefore the sensors could be used for bio sensing and chemical sensing in liquid environment. [3] [5] 
(a)

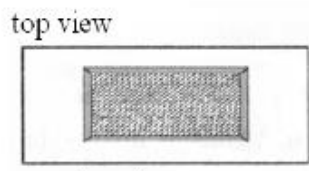

membrane bottom

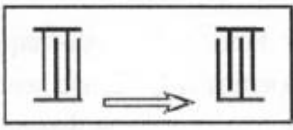

side view

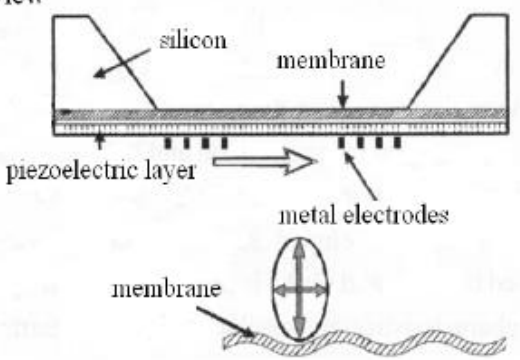

(b)

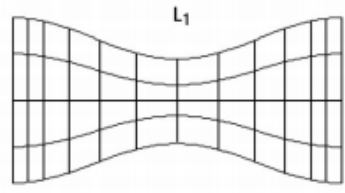

symmetric mode

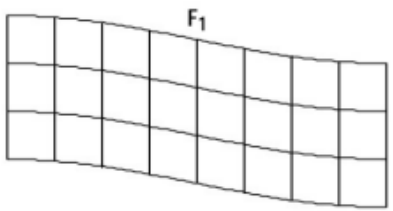

antisymmetric mode

Figure 1.4 (a) Schematic of a flexural plate wave device. The side view shows the Different layers and membrane movement [5]. (b) Symmetric and antysymetric plate mode of a FPW device [6]

The advantages of these devices includes high sensitivity and flexibility of detection at either surface. Their main disadvantages are the fabrication cost (membrane fabrication) and the device fragility.

\section{Love Wave Sensors ( $L W)$}

LW devices are inside the category of SAW devices but shear horizontal surface acoustic waves (SH-SAW) are excited within the piezoelectric substrate. The excitation of this type of waves instead of Rayleigh wave will depend in the piezoelectric crystal cut and orientation [9]. A shear horizontal particle displacements is generated in Love waves (which is parallel to the waveguide surface and perpendicular to the wave propagation direction). The layered structure of the LW sensor consist of a piezoelectric substrate and a guiding layer. These devices have good sensitivity to mass loading (due to the concentration of the wave near the surface) and they can be used in liquid media since compressional waves into the liquid is minimized. Much higher sensitivity in 
liquid media has been observed in comparison to traditional QCM-based sensors. Figure 1.5 present the typical structure of these devices [10].

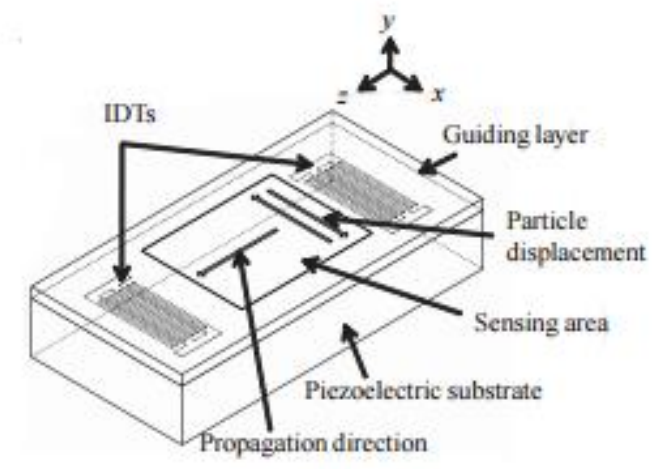

Figure 1.5 Love Wave Sensor Structure [10]

\section{Compression acoustic wave devices}

Table 1.2 summarize the previously described configuration of acoustic wave devices. It is clear that these values are not defining since the use of different materials like film piezoelectrics and novel techniques that allow the reduction of the wave confining structure can maximize the operational frequency as well as the sensitivity, but as a reference point the data is valid. As a conclusion it is observed than SAW and FPW devices are among the most sensitive devices of the acoustic wave devices family. When the media is liquid then Love devices and FPW devices represent the most sensitive configurations. 
Table 1.2 Comparison of the characteristics of different acoustic-wave sensors. Data taken

\begin{tabular}{ccccc} 
& \multicolumn{4}{c}{ from [3] [5] } \\
\hline Sensor type & FRO & $\mathbf{S}_{\mathbf{m}}$ & OL & Mechanical Strength \\
& & & & Med \\
\hline TSM Quartz & 5 to 30 & 12 to 70 & Yes & High \\
\hline SAW & $30-500$ & $100-500$ & No & Med \\
\hline SH-APM & $20-200$ & $20-40$ & Yes & Med-High \\
\hline LW & $100-200$ & $150-500$ & Yes & Low-Med \\
\hline FPW & 5 to 20 & $200-1000$ & Yes &
\end{tabular}

FRO: Frequency of operation $\mathbf{S}_{\mathrm{m}}$ : Surface mass sensitivity OL: Operation in liquid

\subsection{PIEZOLECTRIC MATERIALS FOR SAW DEVICES}

\subsubsection{Bulk and film piezoelectric materials}

The selection of the piezoelectric substrate for the SAW device will be dependant on the application that it will be used for. These requirements and the specific characteristics that each substrate have such as the coefficient of thermal expansion, the electromechanical coupling factor, the wave propagation velocity, the capability that might exist for microelectronic fabrication techniques and cost will determine their selection [9]. SAW devices have been typically fabricated using quartz, $\mathrm{LiNbO}_{3}$ and $\mathrm{LiTaO}_{3}$ as the piezoelectric substrates. In table 1.2 the comparison of different properties for these materials is displayed.

Table 1.2 Common Piezoelectric properties of single crystal substrates for SAW application. Source: [9]

\begin{tabular}{cccccc}
\hline Material & Orientation & Velocity & Tempe & Coupling Factor & Cost \\
\hline Quartz & Y, X & 3159 & -24 & 0 & Low \\
\hline Quartz & Y ST, X & 3159 & 0 & 0.16 & Low \\
\hline Lithium Tantalate & Y, Z & 3230 & 35 & 0.74 & Medium \\
\hline Lithium Tantalate & $167^{\circ} \mathrm{Y}, \mathrm{X}$ & 3394 & 64 & N/A & Medium \\
\hline Lithium Niobiate & $\mathrm{Y}, \mathrm{Z}$ & 3488 & 94 & 4.6 & High \\
\hline Lithium Niobiate & $128^{\circ} \mathrm{Y}, \mathrm{X}$ & 3992 & 75 & 5.6 & High \\
\hline
\end{tabular}


However, there has been an interest in the usage of thin piezoelectric films instead of bulk materials like those previously described. One of the reasons for this interest comes from the desire to be able to excite SAW waves in non-piezoelectric materials with properties such as high propagating velocities in order to be able to work at higher frequencies. Also thin films are attractive for their efficient transformation between mechanical and electrical energy [11]. The biggest difference in bulk and film materials relates to the usage of composite structure over which the film is deposited that will dominate the elastic properties. For surface acoustic wave (SAW) devices thin piezoelectric films such as zinc oxide ( $\mathrm{ZnO})$, aluminum nitride (AIN) and PZT are good candidates for these applications [12]. $\mathrm{ZnO}$ and AlN are commonly used for the fabrication of SAW sensors on Si wafers; these materials are non-ferroelectric piezoelectric with a wurtzite crystal structure. Careful deposition control must be used in order to specifically nucleate and grow along [0001] in order to exhibit piezoelectric response [13]. Therefore, these materials are usually grown by physical vapor deposition methods in order to control the orientation. $\mathrm{Pb}\left[\mathrm{Zr}_{\mathrm{x}} \mathrm{Ti}_{1-\mathrm{x}}\right] \mathrm{O}_{3}(\mathrm{PZT})$ is a ferroelectric material with a perovskite crystal structure. The particular $\mathrm{PbTiO}_{3}-\mathrm{PbZrO}_{3}$ composition near the morphotropic phase boundary (MFB) allows for the best piezoelectric response from which the highest electromechanical properties are obtained in the $\{001\}$ orientation. The ferroelectric PZT composition requires the application of an applied bias to orient the existing dipoles in order to activate the piezoelectric effect. The piezoelectric coupling coefficient of PZT $\left(K^{2}\right)$ is three to four times higher than the $\mathrm{ZnO}$ and $\mathrm{AlN}$ compositions typically used for SAW applications [12]. In addition, crystalline orientation control is not necessary to achieve adequate piezoelectric response, in contrast to $\mathrm{ZnO}$ and $\mathrm{AlN}$, which makes it an attractive piezoelectric thin film for SAW devices. The properties of PZT thin films are highly dependent on temperature, and the piezoelectric coefficient rapidly increases as the Curie temperature of 
approximately $320^{\circ} \mathrm{C}$ is approached [14]. This factor must be taken into account when the SAW device is exposed to alternating temperatures.

\subsubsection{PZT Film as a piezoelectric film for SAW devices}

The substrate on which the PZT is deposited has a large influence on the preferred crystallographic direction in which the PZT grows, as well as, a big influence on the bonding of the PZT to the substrate. If the device will be used in a harsh environment, this second aspect needs to be contemplated as well. The orientation will have a big influence on the piezoelectric properties of the film, and his will affect the performance of the device directly.

Thin film PZT can be deposited by a variety of techniques, but the sol-gel technique is cost effective and provides a means to produce a variety of microstructures. It was shown in previous works that for parallel plate electrodes, the $\{100\}$-oriented PZT (for tetragonal, as well as, rhombohedral structured materials) had a superior performance than $\{111\}$-textured PZT [15] [16]. PZT does not grow automatically in some preferred crystal orientation, and depending on the nature of the substrate and electrodes deposited, variously oriented films may be grown for the sol gel PZT. In order to nucleate the desired $\{100\}-\mathrm{PZT}$, a seed film is required. Typically, a (111) oriented Pt film has been used for this purpose [17]. In order to grow a Pt (111) film, an adhesion layer such as $\mathrm{TiO}_{2}$ or $\mathrm{ZrO}_{2}$ is used. For this type of configuration, in order to achieve the desired transverse piezoelectric effect, a voltage is applied using what is called a parallel plate electrode (PPE). Figure 1.6b shows a schematic of the described the (PPE). The PPE is formed between the embedded Pt film and a conducting electrode that is deposited on top of the PZT film. 
The PZT thin film can be also poled longitudinally (in the plane of the film). Figure 1.6a shows a schematic of the described longitudinal polarization when using IDTs. An interesting effect of the application of an in-plane polarization is that it adds a compressive component to the overall stress to which the film is subjected. This is in opposition to the parallel plate electrode that adds a tensile component [11]. This compressive state reduces the chances of the film cracking which is of great advantage when the film PZT is being used as a part of a device subject to vibrations. It is important to notice that $\{100\}$ oriented PZT film is not the best candidate for in-plane polarization. For tetragonal PZT, either $\{100\}$ or $\{110\}$ orientations can be used, whereas for rhombohedral PZT only $\{110\}$ orientations can be used. For the morphotropic phase boundary composition, both of these orientations will coexist (and eventually the monoclinic). The preferred orientation would be $\{110\}$ since it would allow us to have in-plane polarization in any case. If we grow random inplane orientation of PZT, then during the in-plane-polarization, the contribution of the tetragonal and rhombohedral phases for different out-of-plane orientations will be noticed. PZT film can be then be grown on the $\mathrm{TiO}_{2}$ bonding layer over the oxidized $\mathrm{Si}(100)$ wafer, as it was discussed by Chidambaram et al. [17]

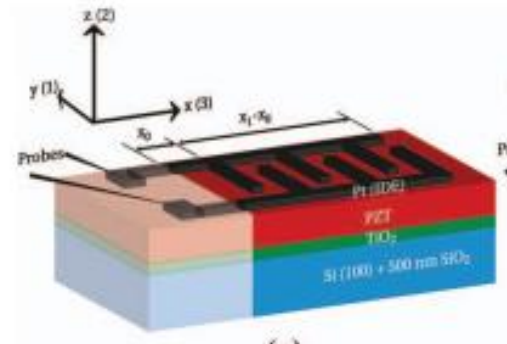

(a)

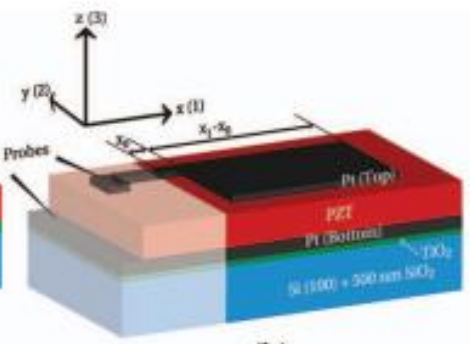

(b)

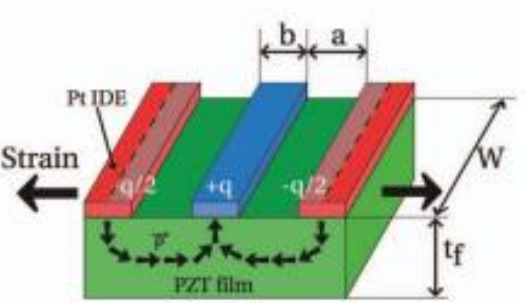

(c)

Figure 1.6 illustration of lead zirconate titanate (PZT) with (a) interdigitated electrode (IDT) system and (b) parallel plate electrode (PPE) (c) IDT unit cell with various parameters, and showing the polarization that develops in the film after poling with the IDT. Source: [11] 


\subsection{CONCLUSION}

This chapter gives a general view of acoustic wave devices used for sensor applications. From the family of acoustic wave devices analyzed it was concluded that for gas sensing applications SAW and FPW devices represent the most sensitive configurations. SAW devices creates waves in the Rayleigh wave mode. In this mode the energy of the propagating wave is concentrated at the surface, the sensitivity of the device to interactions occurring at the surface is then amplified. FPW is a special case of the Rayleigh wave, in which the thickness of the medium that propagates is on the order of the wavelength, and symmetric and antisymmetric modes are created. The disadvantage of SAW devices is that they cannot be used in liquid media since the waves are damped in liquids. FPW devices allows the usage of both surfaces and can be used with liquid media but they are very difficult to fabricate and very fragile.

The selection of the piezoelectric material as the substrate of the SAW device will depend on the application for which they will be used for. Typically single crystal bulk piezoelectric materials have been used in the past. Thin film piezoelectric materials allow the use non-piezoelectric materials for the generated wave to propagate in which permit the increase of the characteristic resonance frequency and this improves the sensitivity even more. Among the piezoelectric thin films $\mathrm{ZnO}$ and AlN represent the non-ferroelectric piezoelectric and PZT the ferroelectric piezoelectric used in SAW devices. PZT has very interesting properties with a larger piezoelectric coefficient and higher coupling coefficient than the $\mathrm{ZnO}$ and AlN. Also, crystalline orientation control is not necessary to achieve adequate piezoelectric response in PZT. PZT can be texturized or randomly-oriented depending on the seed film that is used and the application of a DC bias will orient the dipoles and polarize the film. On the other hand, PZT properties are very dependent on 
temperature, and at high temperatures the material cannot be used, whereas $\mathrm{ZnO}$ and $\mathrm{AlN}$ present greater stability at higher temperatures.

From the analysis presented in this chapter, a micro surface acoustic wave ( $\mu \mathrm{SAW}$ ) device was chosen to be fabricated based on a multi-layered structure with a texturized and randomly-oriented PZT film as the active material. 


\section{CHAPTER 2 SENSOR FABRICATION}

\subsection{INTRODUCTION}

In this chapter the description of the fabrication process of the $\mu \mathrm{SAW}$ device is presented. The process can be broken down into three different major steps because of the nature of the structure.

I. Preparation of the PZT batch with specific compositional characteristics,

II. Fabrication of the multilayered structure over which the film will be deposited and crystalized.

III. Deposition of the interdigitated eletrodes (IDTs) with a specific design.

The following subsections will describe each of these steps. A final subsection will present the challenges that occurred during fabrication and a description of the resolutions encountered.

\subsection{PZT SOL-GEL FABRICATION}

The first step in the preparation of the PZT sol gel solution was the calculation of the concentration of the precursors that were going to be used in the process. Although the vendor specified the concentration of each precursor, it was necessary to corroborate them, since small discrepancies in these values might cause large compositional discrepancies from our desired final product. In order to achieve this, loss-on-ignition (LOI) measurements were performed on all the precursors. 
The following equation was used:

$$
\text { LOI }=\frac{\text { weight of the metal }}{\text { Total weight of the solution }}
$$

In order to make the LOI of the precursors, the initial weight of the crucibles were measured, then approximately $2 \mathrm{~g}$ of the precursor was added and was weighed immediately. The precursors were then thermally oxidized in order to measure the weight of the metal oxide formed. The oxidation temperature used was $1000{ }^{\circ} \mathrm{C}, 1000{ }^{\circ} \mathrm{C}$, and $650{ }^{\circ} \mathrm{C}$ for 2 hours each for $\mathrm{TiO}_{2}, \mathrm{ZrO}_{2}$ and $\mathrm{PbO}$, respectively. Once this process was over, and while the crucibles were still at temperature above $100^{\circ} \mathrm{C}$ in order to avoid water adsorption, they were weighed again. With these values, the LOI values could be calculated. It is also important to acknowledge that for each precursor, five crucibles were used in order to measure a reliable LOI value with its relative error. The LOI results of the precursors used for the synthesis described above are summarized in table 2.1.

Table 2.1 LOI of the different precursors (LOI = weight of the metal / total weight of the solution).

\begin{tabular}{ccccccc}
\hline Precursor & Vendor & Product \# & LOT & $\begin{array}{c}\text { Vendor } \\
\text { LOI }\end{array}$ & $\begin{array}{c}\text { Calculated } \\
\text { LOI }\end{array}$ & Deviation \\
\hline $\begin{array}{c}\text { Lead Acetate Trihydrate } \\
\mathbf{( 9 9 \% )}\end{array}$ & Alfa Aesar & 14242 & L19Y028 & 0.5462 & 0.5521 & $1.07 \%$ \\
\hline $\begin{array}{c}\text { Zirconium(IV) n- } \\
\text { propoxide, 70\% w/w in } \\
\text { n-propanol }\end{array}$ & Alfa Aesar & 44770 & C19Z016 & 0.284 & 0.282 & $0.70 \%$ \\
\hline $\begin{array}{c}\text { Titanium(IV) } \\
\text { isopropoxide, 95\% }\end{array}$ & Alfa Aesar & A13703 & F06Z002 & 0.1674 & 0.1676 & $0.12 \%$ \\
\hline
\end{tabular}


A lead zirconate titanate (PZT) sol-gel precursor was prepared based on reported works in the area [18]. The desired final composition of the PZT corresponded to the morphotropic phase boundary (MPB) composition $\left(\mathrm{Pb}\left[\mathrm{Zr}_{0.52} \mathrm{Ti}_{0.48}\right] \mathrm{O}_{3}\right)$. This composition was selected in order to obtain the optimum piezoelectric properties. The selected concentration values for each precursor were based on the LOI results previously described. It is important to keep in mind that in order to prevent organic precursors from gelating, which occurs when they are in contact with humidity, a controlled atmosphere with no humidity was required. For this, a positive pressure glove box was used with an pure oxygen atmosphere, and the relative humidity was kept a value below $0.1 \%$. The followed steps are listed below.

\section{i. Lead acetate solution preparation}

The first step in the fabrication of a PZT sol is the preparation of the lead acetate solution. This procedure is done inside the glove box to prevent the exposure to moisture. A mass of $37.52 \mathrm{~g}$ of lead acetate trihydrate (\#14242, 99\%, Alfa Aesar) was placed into a $500 \mathrm{ml}$ Pyrex flask. An excess of $5 \mathrm{wt} \%$ of $\mathrm{Pb}$ was used to counter the loss of $\mathrm{PbO}$ during the rapid thermal annealing (RTA) process [19]). After this, $143.52 \mathrm{~g}$ of 2-Methoxyethanol was added to a Pyrex flask. A distillation of this solution under vacuum was done in order to remove any water traces form it and to increase the concentration of lead acetate by partially evaporating the 2-Methoxyethanol. A rotary evaporator BÜCHI model R-205 (Labortechnik AG, Switzerland) was used for this purpose. During this process, the $500 \mathrm{ml}$ Pyrex flask was attached to the distillation unit and it was pressurized with N2. The Pyrex flask was immersed into a bath with silicone oil and warmed up to $120^{\circ} \mathrm{C}$ while rotating at $120 \mathrm{rpm}$. After $20 \mathrm{~min}$, the $\mathrm{N}_{2}$ line to the distillation unit was closed and vacuum was applied slowly. In this process, the solution started to vaporize and the vaporized 
solution condensed in the cooling coils and was separated into another Pyrex flask. The end point of this process is the formation of a white paste after which the rotation speed is decreased to 35 rpm and the $\mathrm{N}_{2}$ valve is opened to equalize the pressure. Finally, the solution was cooled to room temperature.

\section{ii. Zr/Ti solution preparation}

The second step is the preparation of the $\mathrm{Zr} / \mathrm{Ti}$ solution. It was also completed inside the glove box to prevent the exposure to moisture. A mass of $21.53 \mathrm{~g}$ of $\mathrm{Zr}$ n-propoxide $(\# 44770,70 \% \mathrm{w} / \mathrm{w}$ in n-propanol, Alfa Aesar) and $15.34 \mathrm{~g}$ of Ti iso-propoxide (\#A13703, 95\%, Alfa Aesar)were added into a $150 \mathrm{ml}$ Erlenmeyer flask with $43.05 \mathrm{~g}$ of 2-Methoxyethanol and a magnet stir bar. This solution was stirred at $60 \mathrm{rpm}$ until needed. The lead acetate was introduced into the glove box to prevent contact with moisture. The $\mathrm{Zr} / \mathrm{Ti}$ precursor was transferred to the $250 \mathrm{ml}$ Pyrex flask containing the lead acetate. The magnetic stirrer was also transferred. After the $\mathrm{Zr} / \mathrm{Ti}$ precursor transfer, the Erlenmeyer was rinsed with $36.73 \mathrm{~g}$ with Methoxyethanol in order to insure that no precursors were left behind. This process was completed twice.

\section{iii. Reflux of the solution and distillation of the PZT solution}

In order to do the reflux of the solution the $250 \mathrm{ml}$ Pyrex containing $\mathrm{Pb} / \mathrm{Zr} / \mathrm{Ti}$ and 2Methoxyethanol was attached to the distillation unit. A positive $\mathrm{N}_{2}$ pressure was applied and it was refluxed for 3.5 hours at $120^{\circ} \mathrm{C}$ and $120 \mathrm{rpm}$. When the reflux was finalized, the $\mathrm{N}_{2}$ valve was closed and the vacuum was applied up to 8-10 inches of $\mathrm{Hg}$ for 5 minutes. This step removed approximately $10 \mathrm{ml}$ of the by-product. After this step, the vacuum valve was closed, the $\mathrm{N}_{2}$ valve was slowly opened and the distiller was cooled down for 10 minutes in order to decrease the vapor 
temperature. Finally the Pyrex flask was removed from the oil bath and it was cooled down while rotating at $35 \mathrm{rpm}$. As a drying control agent, $8.42 \mathrm{~g}$ of formamide (14835 ACS, 99.5+\%, Alfa Aesar) was added and the solution was stored for future use in the fabrication of thin film of PZT. The final product consisted on $130 \mathrm{~g}$ of PZT sol gel precursor.

\subsection{FABRICATION OF THE SUBSTRATE AND $\mu$ DEVICE}

\subsubsection{Substrate Fabrication: $\mathrm{Si}_{-} \mathrm{SiO}_{2}-\mathrm{TiO}_{\mathrm{x}} \& \mathrm{Si}_{-} \mathrm{SiO}_{2}-\mathrm{TiO}_{\mathrm{x}}-\mathrm{Pt}$}

A $7.62 \mathrm{~cm}$ ( 3 inch) $\mathrm{Si}<100>$ oriented wafer was first cleaned following the RCA process inside the cleanroom. The wafer was thermally oxidized in an air atmosphere at $1100^{\circ} \mathrm{C}$ for 3 hours. In figure 2.1 the growth $\mathrm{SiO}_{2}$ as a function of time under the mentioned conditions is plotted. The data points were calculated from [2.10] and the thickness was confirmed using a J.A. Woollam M2000U White Light Ellipsometer to be $\sim 1200 \mathrm{~nm}$ of $\mathrm{SiO}_{2}$. The wafer was then sputtered with 30 $\mathrm{nm}$ of $\mathrm{Ti}$ and then thermally oxidized at $800^{\circ} \mathrm{C}$ for 20 minutes to obtain $\mathrm{TiO}_{\mathrm{x}}$. At this point the desired $\mathrm{Si}_{-} \mathrm{SiO}_{2}-\mathrm{TiO}_{\mathrm{x}}$ substrate was obtained. Taking a step further, $300 \mathrm{~nm}$ of Pt were sputtered on top of the $\mathrm{Si}_{-} \mathrm{SiO}_{2}-\mathrm{TiO}_{x}$ and finally annealed at $700{ }^{\circ} \mathrm{C}$ to obtain the $\mathrm{Si}_{-} \mathrm{SiO}_{2}-\mathrm{TiO}_{\mathrm{x}}-\mathrm{Pt}$ substrate. After this, the wafer was diced into four smaller square pieces using a wafer dicer Disco DAD3240 (DISCO Kiru-Kezuru-Migaku Technologies, Tokyo, Japan) of 1" by 1" to be later processed for sensor fabrication. 


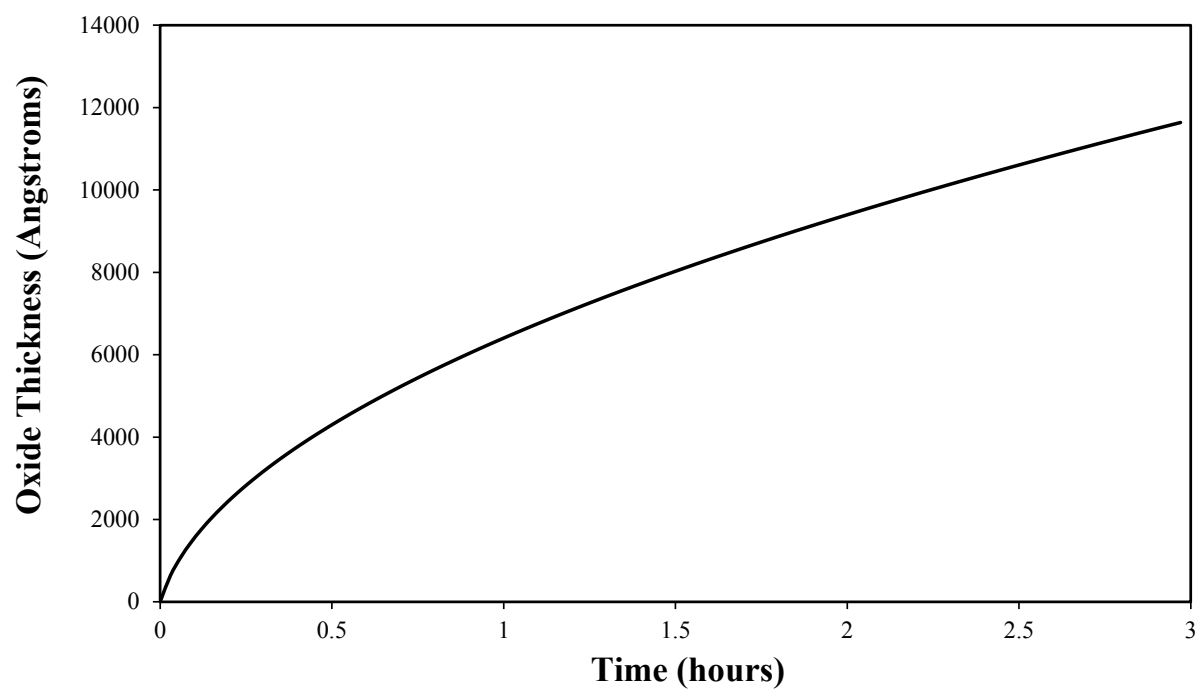

Figure 2.1 Thermal Growth of $\mathrm{SiO}_{2}$. Conditions: $1100^{\circ} \mathrm{C}$ in air atmosphere. Data points obtained from

\subsubsection{PZT thin film deposition}

In order to fabricate the PZT film of uniform thickness, the material needed to be prepared in solution and then applied to a substrate, one coating at a time. It is important to notice that this same procedure was repeated for all our multilayer substrates.

The process was done in a class 100 cleanroom inside a negative pressure hood in order to avoid contamination of the film while processing, as well as to avoid contamination of the environment where the work was being done. A $10 \mathrm{ml}$ syringe was loaded with the prepared solution previously described. In order to filter any particle present in the solution a 0.1 micron filter was attached to the syringe. The wafer was then placed in the spin coater and the PZT solution was deposited with the syringe over all the surface of the substrate surface. The method used a 10 second spin at 400 rpm followed by a 45 second spin at $2500 \mathrm{rpm}$ with an acceleration of $400 \mathrm{rpm} / \mathrm{second}$ each. The substrate was then placed on a hot plate at $150{ }^{\circ} \mathrm{C}$ for 2 minutes in order to evaporate the solvent. The sample was transferred to another hot plate set at $350^{\circ} \mathrm{C}$ for 7 minutes for pyrolysis. The 
substrate was cooled down in air. These steps were repeated 3 times to obtain $\sim 300 \mathrm{~nm}$ of a thin film. Samples were annealed in an AnnealSys As-Micro rapid thermal annealer (RTA) system (AnnealSys SAS, Montpellier, France) at $700^{\circ} \mathrm{C}$ for $1 \mathrm{~min}$, with a ramp of $5^{\circ} \mathrm{C} / \mathrm{s}$. In figure 2.2, the illustration of the described steps that were followed during spin coating process are presented.

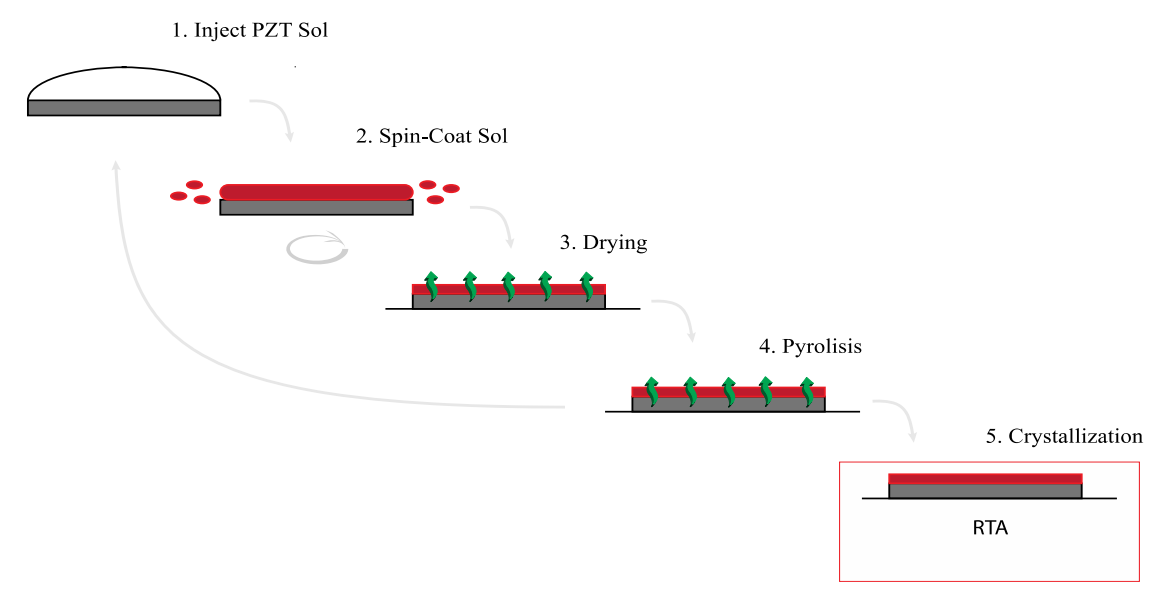

Figure 2.2 Schematic Illustration of the PZT thin film fabrication.

\subsubsection{IDTs Deposition}

The micro surface acoustic wave device fabrication required the deposition of interdigitated electrodes (IDTs) with a specific design over the surface of the composite $\mathrm{Si}_{-} \mathrm{SiO}_{2}-\mathrm{TiO}_{\mathrm{x}}-\mathrm{PZT}$ and $\mathrm{Si}-\mathrm{SiO}_{2}-\mathrm{TiO}_{\mathrm{x}}-\mathrm{Pt}-\mathrm{PZT}$ structures. Since the dimensions are in the micrometer range the sharpness 
of the IDTs must be very high. For this reason, optical photolithography and sputtering techniques were used to deposit the IDTs.

The IDTs were deposited using a standard lift-off process. Image reversal photoresist AZ 5214E was used for this purpose. The process consisted of spin-coating the photoresist at $3500 \mathrm{rpm}$ to obtain a $1.5 \mu \mathrm{m}$ thickness. The film was prebaked at $100^{\circ} \mathrm{C}$ for $1 \mathrm{~min}$ using a hot plate. The film was then exposed to $50 \mathrm{~mJ} / \mathrm{cm}^{2}$ using the Karl Süss MA6/BA6 mask aligner (SÜSS Micro Tec AG, Garching, Germany) with the designed mask. The steps that followed this process were a reversal bake at $120^{\circ} \mathrm{C}$ for 2 min using a hotplate (most critical step), flood exposure (energy $>200$ $\mathrm{mJ} / \mathrm{cm}^{2}$ ) and finally the development of the photoresist using AZ400 (1:4 water) for 1 min. The image was checked using an optical microscope to observe the development and the resolution of the edges. A thin film of titanium/platinum was sputtered using argon as the selected atmosphere and keeping the sputtering station closed during the process. Excessive oxidation of the titanium before depositing Pt was avoided using this process. The Pt film was lifted by introducing the sputtered substrates into an acetone bath set at $60^{\circ} \mathrm{C}$ with gentle agitation for 15 min followed by an isopropanol wash. The final film was dried with a nitrogen gun.

\subsection{CHALLENGES AND RESOLUTION ENCOUNTERED}

\section{DURING FABRICATION}

During the sensor fabrication, we encountered a number of unexpected challenges that we had to solve in order to carry on with the sensor investigation. After the film deposition, the characterization of the film demonstrated noticeable porosity and cracks on the film which would 
highly impact the piezoelectric response of the sensor. Also, after the IDTs deposition and while testing the sensors, we noticed a great degradation of the film produced by delamination of the structure. The analysis, as well as, the resolution of these challenges are explained in the following section.

\subsubsection{Film porosity}

The surface was characterized by SEM microscopy. As previously described, the PZT film was deposited over the $\mathrm{Si} / \mathrm{SiO}_{2} / \mathrm{TiO}_{\mathrm{x}}$ structure which initially displayed a highly porous surface in parts of the film. Figure 2.3a presents a SEM micrograph of the sample in which spherical pores across the surface of the PZT structure can be seen. After an analysis of this image, it was concluded that the porosity was related to the abrupt evaporation of the solvent of the sol PZT. While spin coating the PZT, a drying step followed by a pyrolysis was performed to each deposited layer before the crystallization step. If during these steps, the solvent and organics are not completely evaporated and burned out, then these organics may remain embedded in the film and will be later removed as a gas phase at once during the RTA process. The pores represent the empty space where the solvent and organics were present. The substrate was then placed on a hot plate at $150^{\circ} \mathrm{C}$ for $2 \mathrm{~min}$ in order to evaporate the solvents, and the wafer was later transferred to another hot plate set at $350^{\circ} \mathrm{C}$ for $7 \mathrm{~min}$ for pyrolysis. The RTA process was not modified. In figure $2.3 \mathrm{~b}$, the SEM image is shown for the PZT film surface after the previously mentioned modification in the deposition method was introduced. It can be clearly seen that the porosity was completely eliminated. 

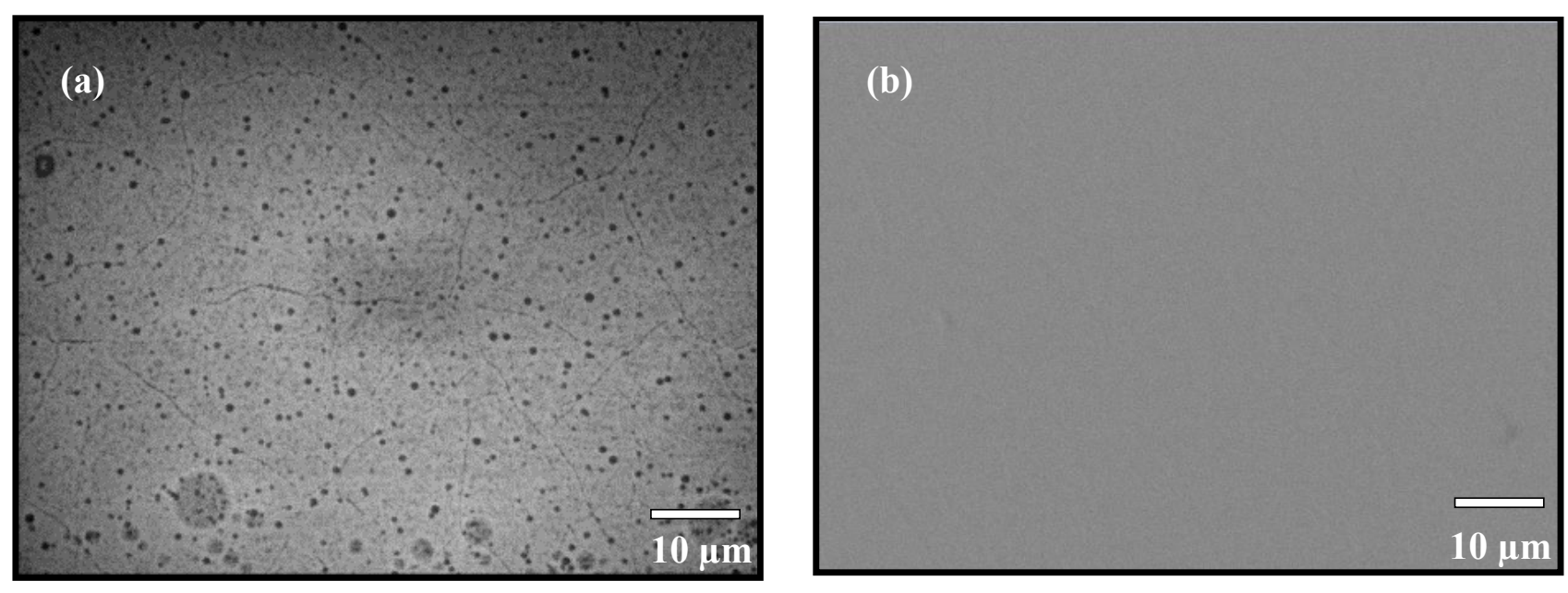

Figure 2.3 Scanning electron microscope (SEM) image of randomly oriented PZT. (White bar $=10 \mu \mathrm{m}$ ). (a) Porous PZ film. Conditions for evaporation and pyrolysis steps: hot plate $150^{\circ} \mathrm{C}$ for 1 minutes $\& 350^{\circ} \mathrm{C}$ for 3 minutes, (b) SEM image of a non-porous PZT film. Conditions for evaporation and pyrolysis steps: hot plate $150^{\circ} \mathrm{C}$ for 3 minutes $\& 350^{\circ} \mathrm{C}$ for 7 minutes.

\subsubsection{Film Delamination and Cracking}

Figure 2.4a presents the atomic force microscope (AFM) amplitude retrace images captured on tapping mode of the surface of the PZT deposited on the $\mathrm{Si} / \mathrm{SiO}_{2} / \mathrm{TiO}_{\mathrm{x}}$ substrate. In the image a film discontinuity in a crack type of shape is observed. These cracks were not identified with the optical microscope nor scanning electron microscope. There are two major implications to the observed film discontinuities. One, the ferroelectric properties of the film are diminish, and second, the acoustic wave that travels over the surface will be affected in a non-predictable way. If the film is analyzed on detail it can be seen that close to the film discontinuities the height of the film increases. This effect makes us believe that a delamination issue is occurring between the film and the substrate due to cohesion issues and then film breaks apart releasing contain energy. This observed effect was correlated with temperature gradients created over the surface. As a result, it was decided to change the heating and cooling rate from $\pm 20^{\circ} \mathrm{C} / \mathrm{s}$ to $\pm 5^{\circ} \mathrm{C} / \mathrm{s}$. Figure $2.4 \mathrm{~b}$ presents the AFM amplitude retrace image of the PZT film deposited on the $\mathrm{Si} / \mathrm{SiO}_{2} / \mathrm{TiO}_{\mathrm{x}}$ substrate after 
the modification previously described. It can be seen that cracks were eliminated and a decrease in the grain size of PZT was observed.
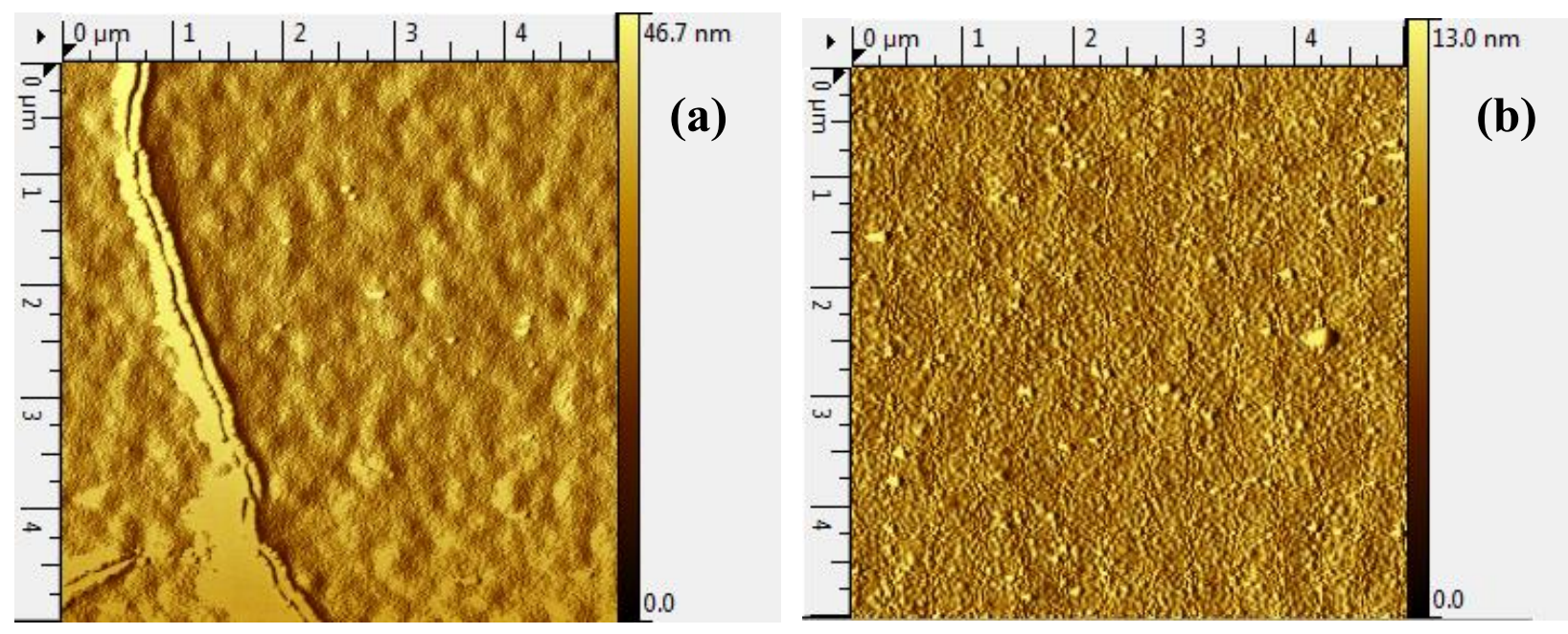

Figure 2.4 Atomic force microscope (AFM) amplitude retrace image ( $5 \mu \mathrm{m}$ by $5 \mu \mathrm{m})$ measured on tapping mode of PZT deposited over $\mathrm{Si} / \mathrm{SiO}_{2} / \mathrm{TiO}_{\mathrm{x}}$. (a) Conditions: annealing at $700^{\circ} \mathrm{C}$ for 1 minute with heating and cooling rates of $\pm 20^{\circ} \mathrm{C} / \mathrm{s}$. (b) Conditions: annealing at $700^{\circ} \mathrm{C}$ for 1 minute with heating and cooling rates of $\pm 5^{\circ} \mathrm{C} / \mathrm{s}$.

\subsubsection{Film Delamination}

After fabricating $\mathrm{Si} / \mathrm{SiO}_{2} / \mathrm{TiO}_{\mathrm{x}} / \mathrm{PZT}$ and $\mathrm{Si} / \mathrm{SiO}_{2} / \mathrm{TiO}_{\mathrm{x}} / \mathrm{Pt} / \mathrm{PZT}$ multilayered structures on a 1 " by 1" silicon wafer. The Scotch ${ }^{\circledR}$ tape adhesion test was performed on the surface of the material [20]. To our surprise, we noticed that the $\mathrm{Si} / \mathrm{SiO}_{2} / \mathrm{TiO}_{\times} / \mathrm{Pt} / \mathrm{PZT}$ structure would delaminate in the majority of cases when the tape was peeled from or up to the film limits. These results were also observed when drying $\mathrm{N}_{2}$ was aimed laterally at the film. In figure $2.5 \mathrm{~b}$, an optical microscope image taken of the delaminated surface is displayed. An elemental analysis of the delaminated surfaces were completed with energy dispersive X-ray (EDX). In figure 2.5a, the measured spectrum of the delaminated surface is shown. Traces of $\mathrm{Si}, \mathrm{O}$ and $\mathrm{Ti}$ were noticed, but no traces of Pt were observed. This observation was repeated and was found to be consistent with the results 
found. It was concluded that the delamination was occurring in the interface of the $\mathrm{TiO}_{\mathrm{x}}$ and the Pt. We tried different techniques to eliminate the delamination; a few of these techniques were as follows: 1) $\mathrm{O}_{2}$ plasma etching to the $\mathrm{TiO}_{\mathrm{x}}$ surface before sputtering deposition, 2) annealing the film after Pt deposition for thermal stress relaxation, and 3) thermal sputtering of Pt to increase order. None of these processes succeeded in avoiding these issues. This effect limits the usage of a device based on the $\mathrm{Si} / \mathrm{SiO}_{2} / \mathrm{TiO}_{\mathrm{x}} / \mathrm{Pt} / \mathrm{PZT}$ structure, especially when it is exposed to gas impacting longitudinally to the surface.

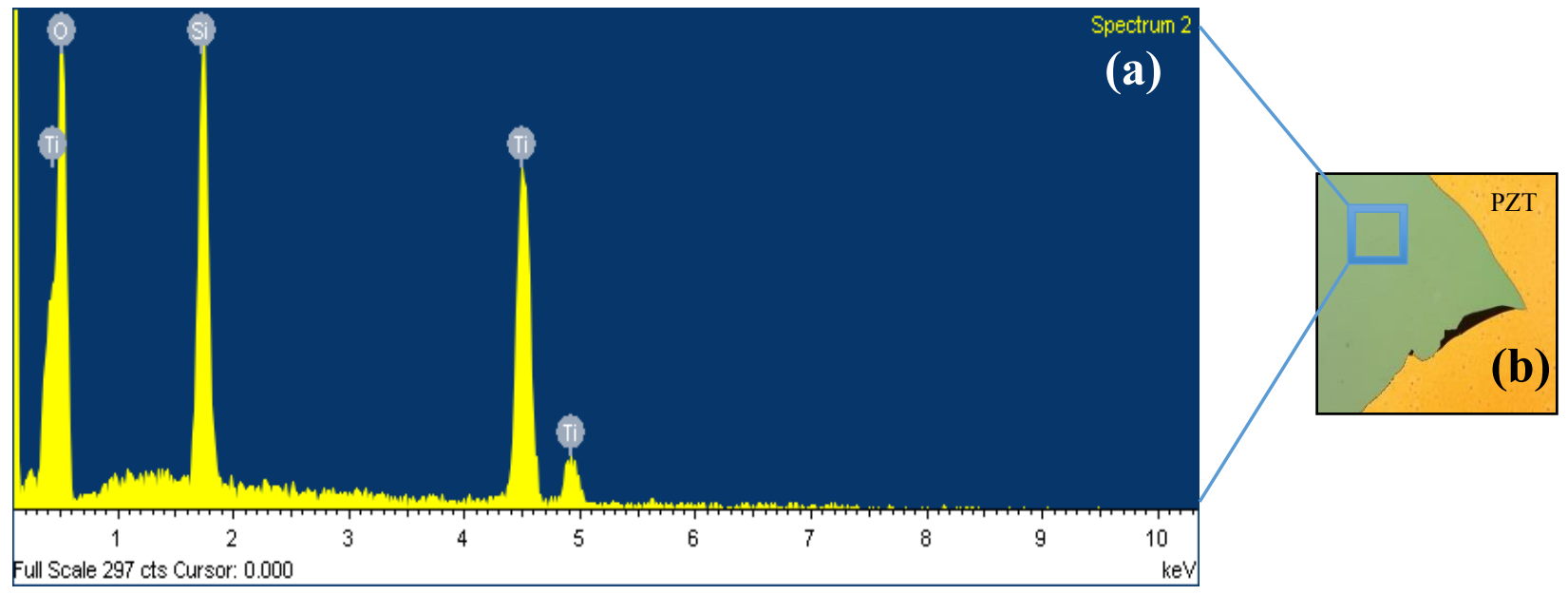

Figure 2.5 (a) Energy dispersive X-ray (EDX) spectrum over delaminated surface of the $\mathrm{Si} / \mathrm{SiO}_{2} / \mathrm{TiO}_{\mathrm{x}} / \mathrm{Pt} / \mathrm{PZT}$. The elements that were observed are: $\mathrm{Si}, \mathrm{O}$ and Ti. (b) optical microscope image of the delaminated film is observed.

\section{CONCLUSIONS}

SAW devices with two different multilayered structures: $\mathrm{Si} / \mathrm{SiO}_{2} / \mathrm{TiO}_{\times} / \mathrm{PZT}$ and $\mathrm{Si} / \mathrm{SiO}_{2} / \mathrm{TiO}_{x} / \mathrm{Pt} / \mathrm{PZT}$, were successfully fabricated. The complexity of the process required the separate preparation of the PZT sol-gel batch, the composite substrate fabrication and the spin coating and crystallization of the PZT onto the substrates. While inspecting the surface of the PZT film with AFM and SEM techniques it was noticed a high porosity and delaminating-cracking of the PZT film. These challenges were successfully solved by modifying the sol spin coating stage 
and the rapid thermal annealing (RTA) stage. The PZT deposited over the $\mathrm{Si} / \mathrm{SiO}_{2} / \mathrm{TiO}_{x} / \mathrm{Pt}$ structure was delaminated when scotch tape test was performed from and up to the limits of the surface. An EDX study of the delaminated surface was performed and it was identified that the delamination was occurring between the TiOx-Pt films. Different approaches to improve this adhesion including $\mathrm{O}_{2}$ plasma etching to the $\mathrm{TiO}_{\mathrm{x}}$ surface before sputtering deposition, annealing the film after Pt deposition for thermal stress relaxation and thermal sputtering of Pt to increase order were performed. None of these processes succeeded in avoiding the delamination. Since no delamination occurred in the $\mathrm{Si} / \mathrm{SiO}_{2} / \mathrm{TiO}_{\mathrm{x}} / \mathrm{PZT}$ composite, this structure would be more convenient to be used as the substrate for the SAW device since less risks of failing while in use exist. 


\section{CHAPTER 3}

\section{ACTIVE LAYER CHARACTERIZATION: A COMPARATIVE STUDY OF $\{100\}$ PZT AND RANDOMLY ORIENTED PZT}

\subsection{INTRODUCTION}

Since the SAW device performance directly depends on the properties of the piezoelectric material and the substrate on which the surface acoustic wave will be propagating, it is required to make a deep characterization of the multilayered structure prior to studying the response of the SAW devices.

This chapter presents the results from a compositional and elementary analysis completed on the PZT films after they were deposited onto the $\mathrm{Si}_{-}-\mathrm{SiO}_{2}-\mathrm{TiO}_{\mathrm{x}}$ and $\mathrm{Si}-\mathrm{SiO}_{2}-\mathrm{TiO}_{\mathrm{x}}-\mathrm{Pt}$ multilayered structures. X-ray diffraction (XRD), scanning electron microscopy (SEM) and Atomic Force Microscopy (AFM) were the techniques used for this purpose. A static contact angle method was performed to estimate the surface energy of the PZT films. Finally in order to study the performance of the piezoelectric films a ferroelectric hysteresis loop (P-V curves), leakage (I-V) curves and capacitance $(\mathrm{C}-\mathrm{V})$ curves were measured longitudinally using the interdigitated electrodes (IDTs). 


\subsection{Crystallographic characterization: XRD}

To characterize the crystallographic structure a Rigaku RU-300 X-Ray diffractometer was used. Figure 3.1 presents the measured XRD pattern of the PZT deposited film over $\mathrm{Si} / \mathrm{SiO}_{2} / \mathrm{TiO}_{\mathrm{x}}$ multilayer structure that was described in detail in chapter 2 . To study the optimum annealing temperature, the PZT was annealed at $700^{\circ} \mathrm{C}, 750^{\circ} \mathrm{C}$ and $800^{\circ} \mathrm{C}$ for $60 \mathrm{~s}$. In the three cases, the perovskite characteristic pattern (JCPDS 00-033-0784) was observed. It is clear that there is a coexistence of different orientations of PZT $(\{100\},\{110\},\{111\},\{200\})$ making the film randomly-oriented due to the lack of a highly oriented template. The pattern also displays peaks that correspond to the $\mathrm{TiO}_{2}$ (JCPDS 03-065-0192) layer underneath the PZT. Studies have mentioned that the growth orientation preference in PZT is highly influenced by the surface free energy of PZT, as well as, the lattice mismatch between the substrate and the PZT crystallographic planes [21] [22]. The chosen annealing temperature for the randomly oriented PZT was $700^{\circ} \mathrm{C}$. The reason of this is mainly due to the increase of annealing temperature resulting in $\mathrm{PbO}$ volatilization and this would generate a compositional shift from the morphotropic phase boundary (MPB), which is undesired. For the PZT annealed at $700^{\circ} \mathrm{C}$, the relative intensity ratios $(\alpha)$ between PZT $\{110\}$ and PZT $\{100\},\{111\}$ and $\{200\}$ are $41.57 \%, 12.77 \%$ and $15.99 \%$, respectively.

Figure 3.2a presents the measured XRD pattern of the film PZT deposited over $\mathrm{Si} / \mathrm{SiO}_{2} / \mathrm{TiO}_{\mathrm{x}} / \mathrm{Pt}$. The analyzed PZT was annealed at $700^{\circ} \mathrm{C}$ for $60 \mathrm{~s}$. The selected annealing temperature was the result of previous studies made that resulted in this temperature (as desired), since at lower temperatures the pyrochlore phase is formed, and at higher temperatures volatilization of $\mathrm{PbO}$ results in a compositional shift from the desired morphotropic phase boundary. The XRD pattern 
corresponds to a perovskite structure (JCPDS 00-033-0784). An intense peak that corresponds to the $\mathrm{Pt}$ (111) layer underneath the PZT film is also identified. A predominantly $\{100\}$-oriented PZT is observed which is in agreement to what it was expected, since the (111) oriented platinum layer is acting as a template for this particular orientation of PZT to grow. Figure 3.2b presents the previously analyzed XRD pattern corresponding the randomly oriented PZT film deposited over $\mathrm{Si} / \mathrm{SiO}_{2} / \mathrm{TiO}_{\mathrm{x}}$ and annealed at $700^{\circ} \mathrm{C}$.

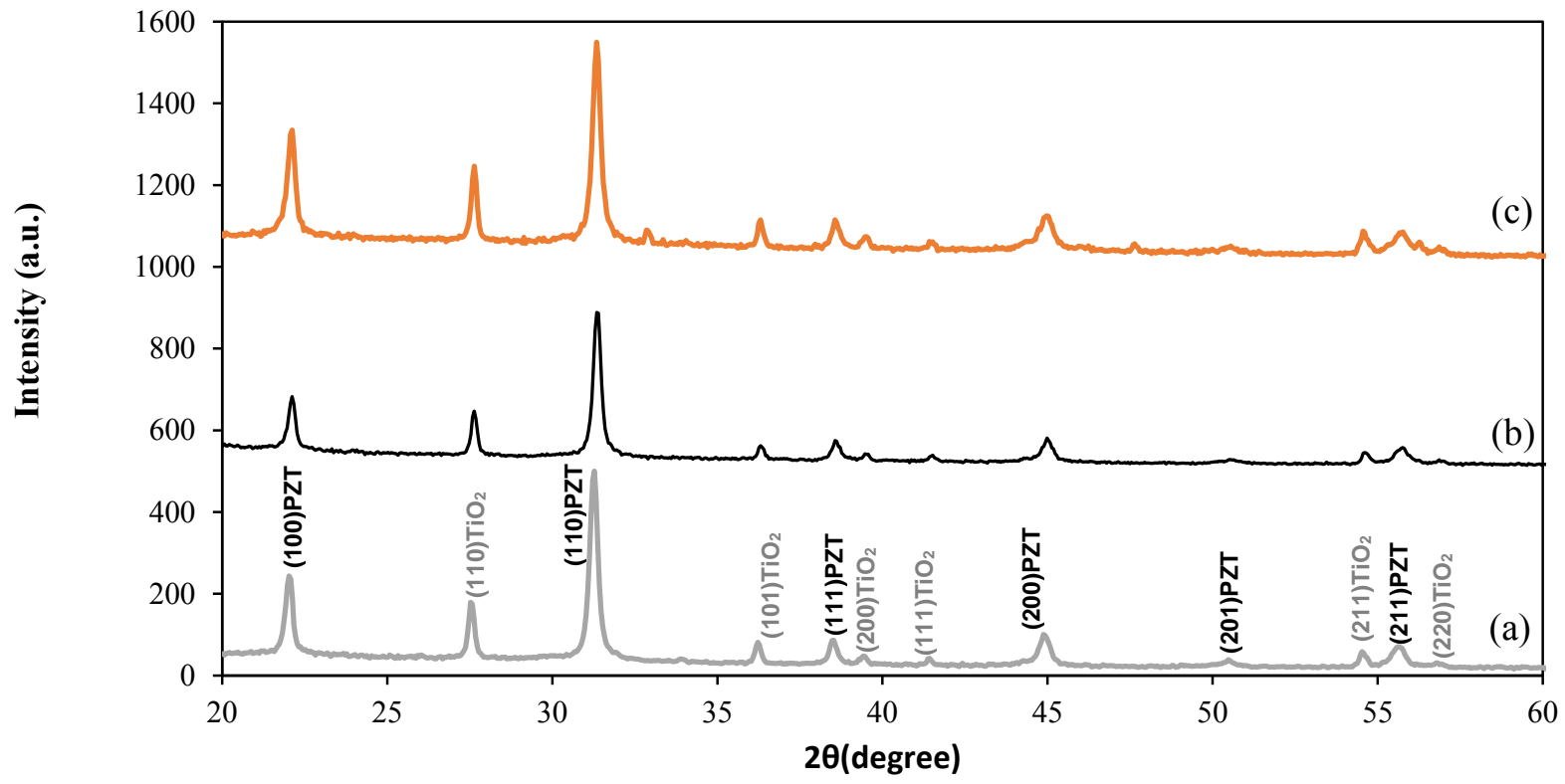

Figure 3.1 XRD characterization pattern of film PZT deposited over $\mathrm{Si} / \mathrm{SiO}_{2} / \mathrm{TiO}_{2}$. (a) PZT annealed at $700{ }^{\circ} \mathrm{C}$ for $60 \mathrm{~s} \mathrm{(b)} \mathrm{PZT} \mathrm{annealed} \mathrm{at} 750{ }^{\circ} \mathrm{C}$ for $60 \mathrm{~s} \mathrm{(c)} \mathrm{PZT} \mathrm{annealed} \mathrm{at}$ $800{ }^{\circ} \mathrm{C}$ for $60 \mathrm{~s}$ 


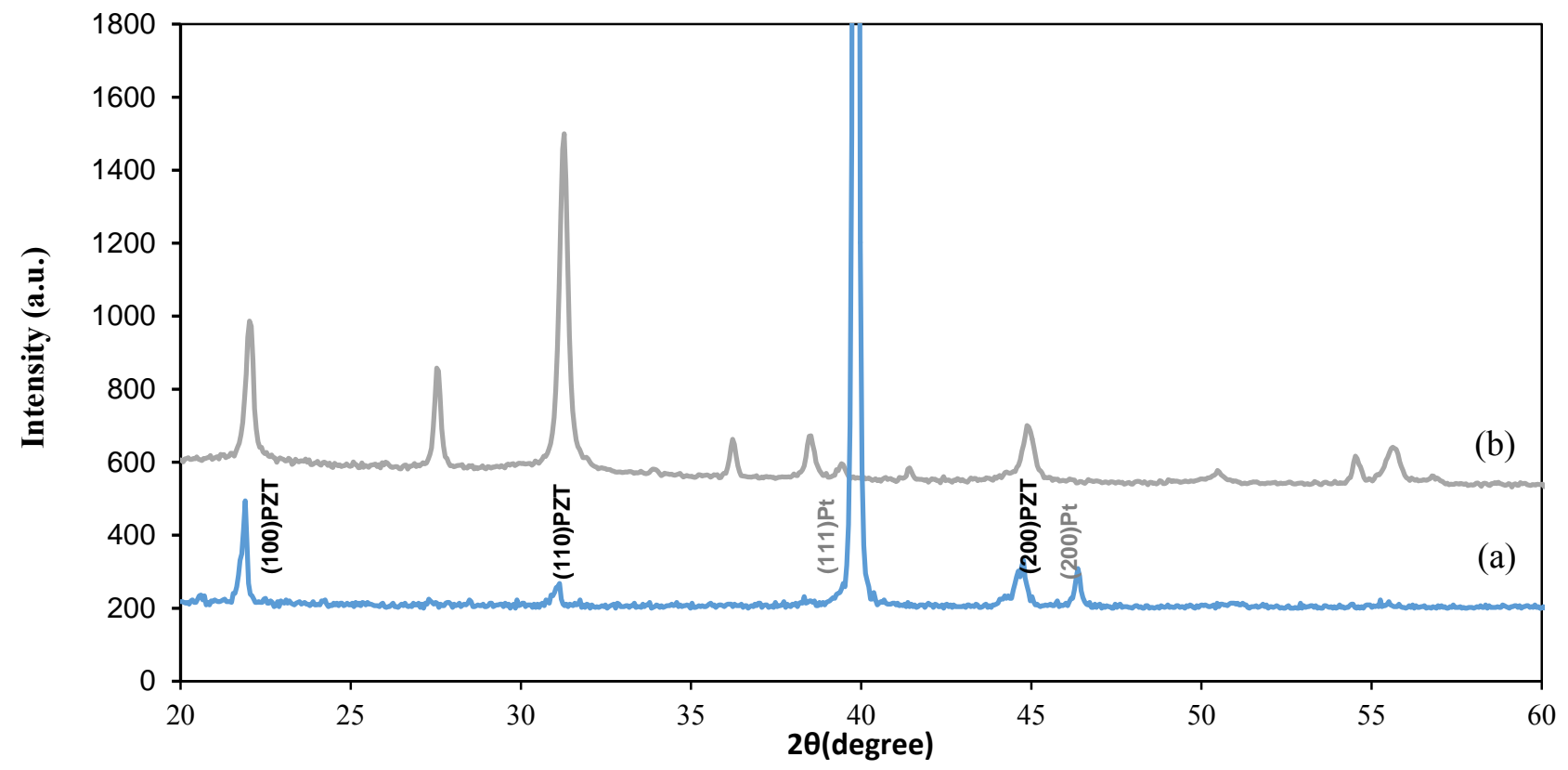

Figure 3.2 XRD characterization of film PZT. (a) PZT deposited over $\mathrm{Si} / \mathrm{SiO}_{2} / \mathrm{TiO}_{2} / \mathrm{Pt}$ and (b) PZT deposited over $\mathrm{Si} / \mathrm{SiO}_{2} / \mathrm{TiO}_{2} / \mathrm{Pt}$. Both systems annealed at $700^{\circ} \mathrm{C}$ for $60 \mathrm{~seconds}$

\subsection{Microstructural Characterization: Atomic Force Microscope}

\section{(AFM)}

Figure 3.3 presents the AFM high retrace 3D and 2D images captured on tapping mode of (a) randomly oriented PZT and on (b) $\{100\}$ texturized PZT. The images were analysis using the Gwyddion software [23] and in table 3.1 the grain size average, standard deviation and RMS roughness derived from AFM images are displayed. In randomly oriented PZT, it was found that the grain size average was $45.82 \mathrm{~nm}$ with a standard deviation of $23.3 \mathrm{~nm}$ and the surface roughness (RMS average of peaks and valleys) was $2.064 \mathrm{~nm}$. In $\{100\}$ texturized PZT, the grain size average was $57.67 \mathrm{~nm}$ with a standard deviation of $23.65 \mathrm{~nm}$ and a surface roughness $6.49 \mathrm{~nm}$. In both processes, the conditions for crystallization were the same (RTA at $700^{\circ} \mathrm{C}$ for 60 seconds). The 
larger grain size of $\mathrm{PZT}\{100\}$ over $\mathrm{Si} / \mathrm{SiO}_{2} / \mathrm{TiO}_{\mathrm{x}} / \mathrm{Pt}(111)$ can be connected to a lower nucleation density and larger activation energy for the nucleation in comparison to PZT grown over $\mathrm{Si} / \mathrm{SiO}_{2} / \mathrm{TiO}_{x}[24]$.

(a)
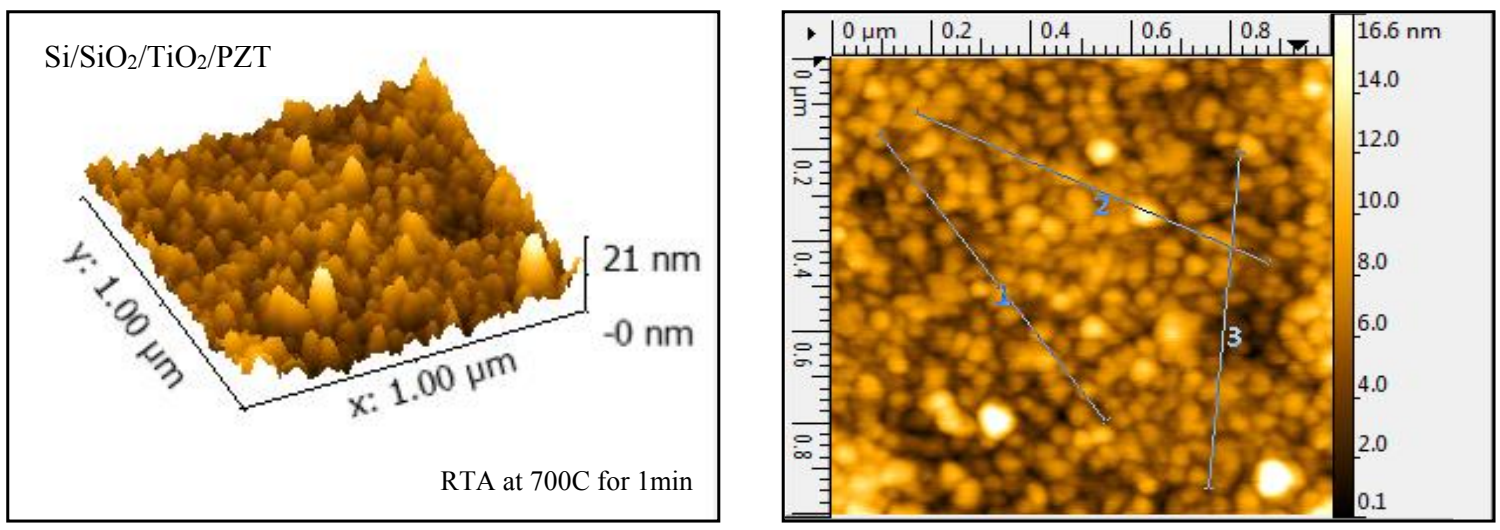

(b)
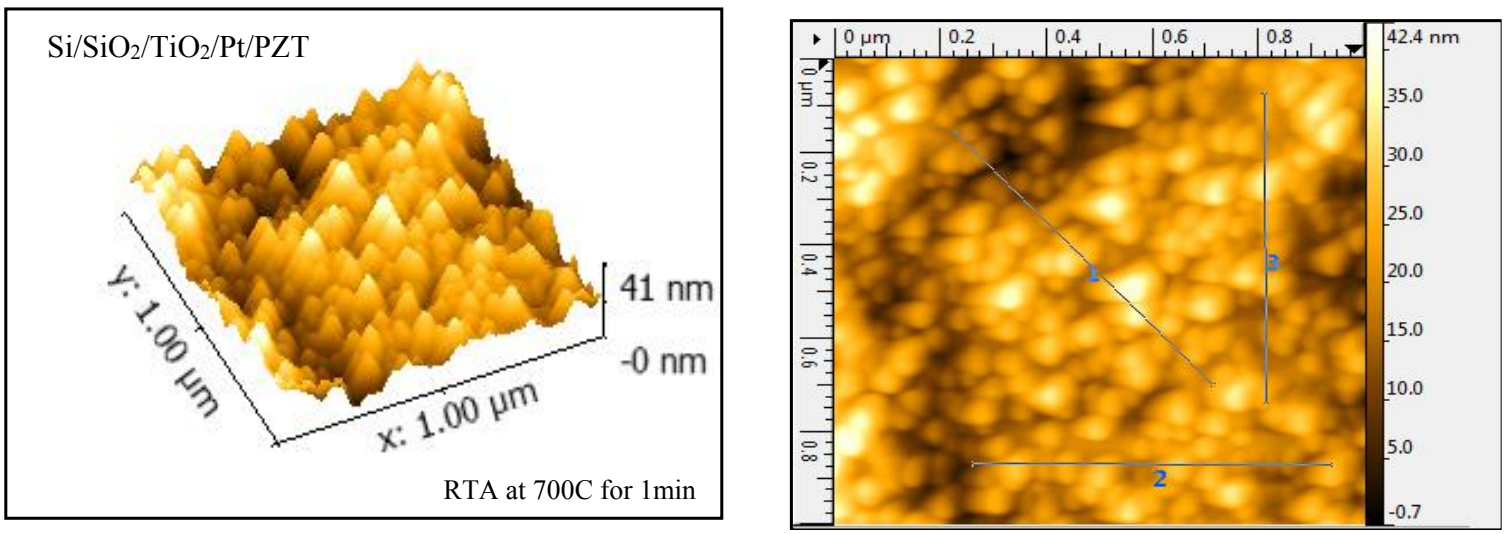

Figure 3.3 AFM high trace 3-D and 2-D image of (a) randomly oriented PZT and (b) (100) Texturized PZT. Both annealed at $700^{\circ} \mathrm{C}$ for 60 seconds. Software used for analyzing images: Gwyddion. [23] 
Table 3.1 Grain size average, GS. Standard deviation and RMS roughness derived from AFM images of (100)-texturized and randomly oriented PZT. Gwyddion Software was used to analyze the images.

Randomly oriented PZT

(100)-Texturized PZT

$\left(\mathrm{Si}_{\mathrm{SiO}} / \mathrm{TiO}_{2} / \mathrm{PZT}\right)$

$\left(\mathrm{Si}_{\mathrm{SiO}} / \mathrm{TiO}_{2} / \mathrm{Pt} / \mathrm{PZT}\right)$

\begin{tabular}{ccc}
\hline Grain Size Average (nm) & 45.82 & 57.67 \\
\hline GS. Standard deviation $(\mathbf{n m})$ & 23.3 & 23.65 \\
\hline Rq (RMS) (nm) & 2.064 & 6.49 \\
\hline
\end{tabular}

\subsection{Contact Angle Measurements}

A contact angle analysis was done over the PZT surfaces using distilled water drops on both multilayered structures $\left(\mathrm{Si} / \mathrm{SiO}_{2} / \mathrm{TiO}_{x} / \mathrm{PZT}\right.$ and $\left.\mathrm{Si} / \mathrm{SiO}_{2} / \mathrm{TiO}_{\mathrm{x}} / \mathrm{Pt} / \mathrm{PZT}\right)$ in order to derive the surface free energy. Fowkes method was used to calculate the surface free energy (SFE) of both PZT films [25] [26]. In table 3.2 the contact angle measurements and SFE derivations are presented. We found in the case of the texturized PZT a high SFE variation, 13.12\%, from the one measured on surface and the ones measured on the film edges. This observed variation is believed to reflect one of the causes of the delamination occurring in the multilayered structure that was described in the previous chapter. The high SFE variation over the surface reflect a stress that exist over the surface which is then released after the delamination occur. It is interesting to note that in the randomly oriented PZT, where no delamination was observed, a small variation of the SFE between the surface center and the film edges was observed. 
Table 3.2 Contact angles, Surface free energy and Lattice Mismatch (with substrate) of PZT (100) and non-texturized PZT.*r.o: randomly oriented

\begin{tabular}{lccccc}
\hline & $\begin{array}{c}\text { Contact Angle } \\
\text { at film center }\end{array}$ & Contact Angle & SFE & SFE & SFE \\
& at film limits & film & film edges & relative \\
& (degree//Standard & (degree//Standard & center & $(\mathbf{m N} / \mathbf{m})$ & variation \\
& Deviation) & Deviation) & $(\mathbf{m N} / \mathbf{m})$ & & $\mathbf{( \% )}$ \\
\hline PZT(100) & $81 / / 0.47$ & $85.5 / / 0.72$ & 81.44 & 70.75 & $13.12 \%$ \\
\hline PZT *r.0 & $75.26 / / 0.54$ & $76.46 / / 0.4$ & 95.64 & 92.57 & $3.2 \%$ \\
\hline
\end{tabular}

In order to have more conclusive results regarding the delamination occurring between $\mathrm{TiO}_{\mathrm{x}}-\mathrm{PT}$ films, a deeper analysis in order to estimate the work of adhesion between these layers would be required.

\subsection{Ferroelectric Characterization}

The randomly oriented PZT was characterized using a Precision LC Ferroelectric Tester (Radiant Technology INC, NM, USA). The measurements completed on the randomly oriented PZT included the longitudinal ferroelectric hysteresis loop, the $\mathrm{C}-\mathrm{V}$ profile, and the $\mathrm{I}-\mathrm{V}$ curve. Interdigitated electrodes (IDEs) with pitch in the range of 2-10 $\mu \mathrm{m}$ were deposited following the photolithography process explained in Chapter 2 . The use of very small IDEs permitted the access to large electric fields (in the order of $300 \mathrm{kV} / \mathrm{cm}$ ).

Figure 3.4 presents longitudinal P-E curves of randomly oriented PZT measured at room temperature using $20 \mathrm{~V}, 30 \mathrm{~V}, 50 \mathrm{~V}$ and $70 \mathrm{~V}$. The distance between the electrodes corresponds to the "finger" distance ( $2 \mu \mathrm{m}$ in this case), and the area is approximated by $2 N t_{f} W$; where $N$ is the number of pairs of electrode "fingers", $t_{f}$ is the thickness of the film, $W$ is the overlap between 
electrodes. One of the assumptions for this approximation was that the electrode finger penetrates through the film thickness and then there would be no dead zones. Table 3.3 displays the parameters of the IDEs that were used to perform the ferroelectric characterization of the randomly oriented PZT film and from which the values of area and separation were calculated. The characteristic ferroelectric hysteresis loop was observed. When $70 \mathrm{~V}$ was used, the remanent polarization of $15.743 \pm 0.1 \mu \mathrm{C} / \mathrm{cm}^{2}$ and the coercive field was $54.143 \pm 1.3 \mathrm{kV} / \mathrm{cm}$.

The longitudinal leakage current measured using the IDEs at room temperature is observed in figure 3.5. The graph has the expected shape showing an increase in leakage current as the voltage is increased, with a tendency to reach a plateau at $\sim 5 \times 10^{-5} \mathrm{~A} / \mathrm{cm}^{2}$. The fact that we have this longitudinal current leakage behavior can be correlated to the poling and de-poling current, as well as, the large number of grain boundaries in the current path.

Figure 3.6. presents the longitudinal permittivity $\left(\varepsilon_{r}\right)$ of the randomly oriented PZT response when a switch linear voltage profile is applied. The permitivity information was aproximated from the $\mathrm{C}-\mathrm{V}$ profile with equation 3.1 , where $\mathrm{C}^{\prime}$ is the measured capacitance and $\varepsilon_{0}$ is the vacuum permitivity.

$$
\varepsilon_{\mathrm{r}}=\frac{\mathrm{C}^{\prime}}{\varepsilon_{0}}\left[\frac{a}{2 N t f W}\right]
$$

The used IDE design correspond to the \#151A from table 3.3. The shape of the response corresponds to the expected pattern, considering that we are measuring the capacitance of piezoelectric material. 


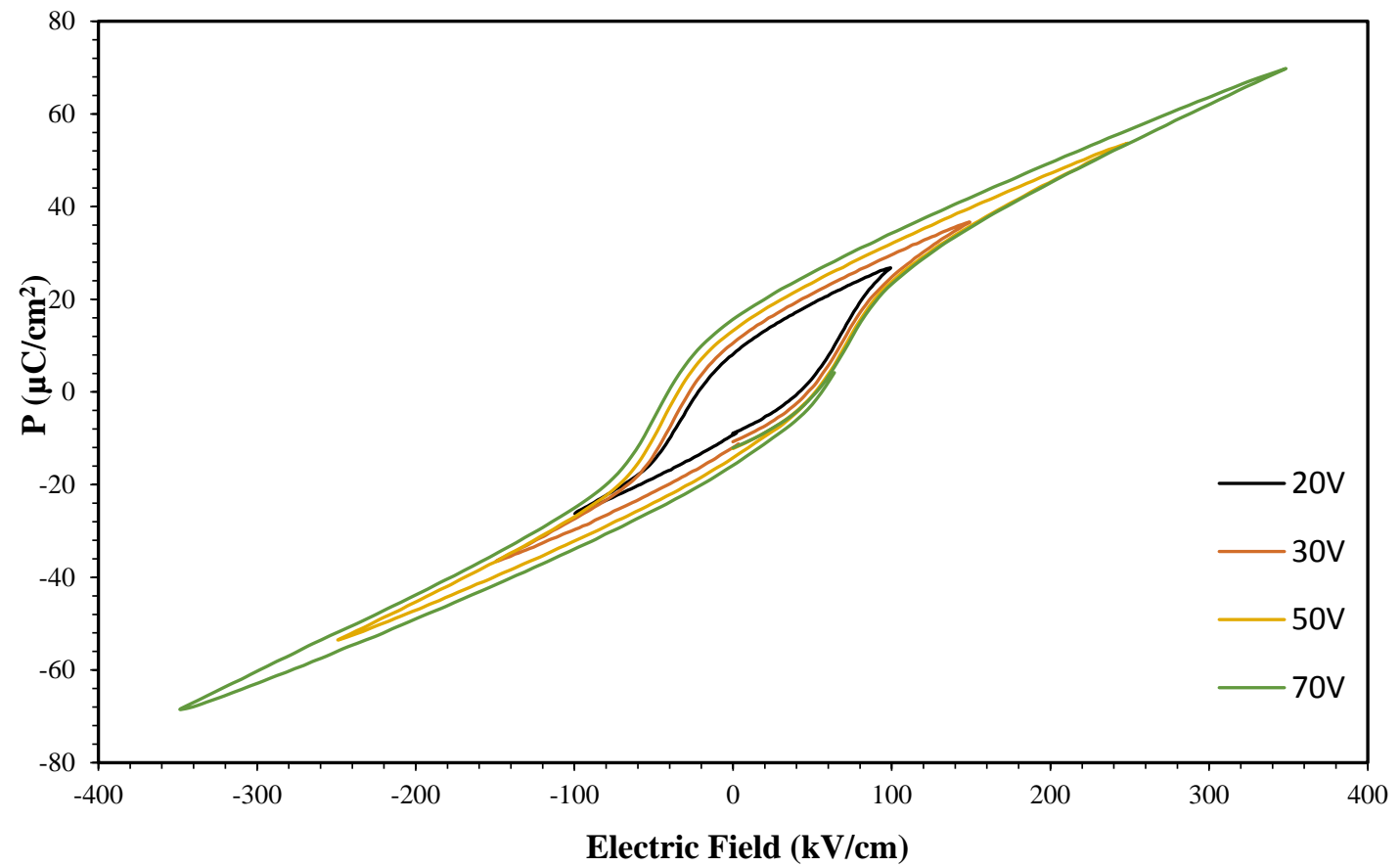

Figure 3.4 Hysteresis loop of randomly-oriented PZT measured longitudinally between interdigitated electrodes (IDEs) with $2 \mu \mathrm{m}$ gap.

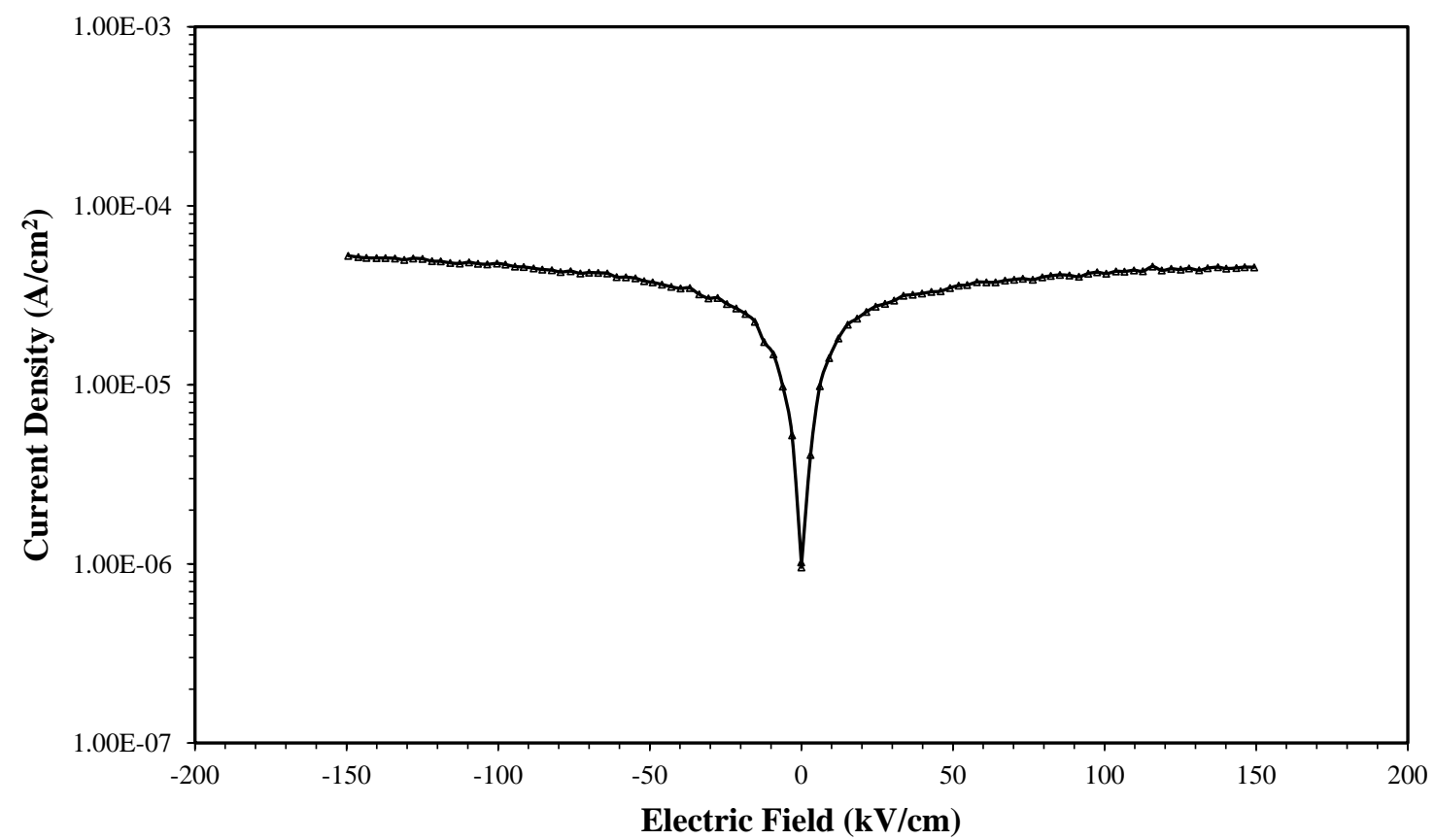

Figure 3.5 IV curves measured longitudinally for randomly oriented PZT between interdigitated electrodes (IDEs) with $2 \mu \mathrm{m}$ gap. (The step preset pulse voltage and width was $4 \mathrm{~V}$ and $1 \mathrm{~ms}$, the measured time, soak time and step delay were set at $100 \mathrm{~ms}$ each) 


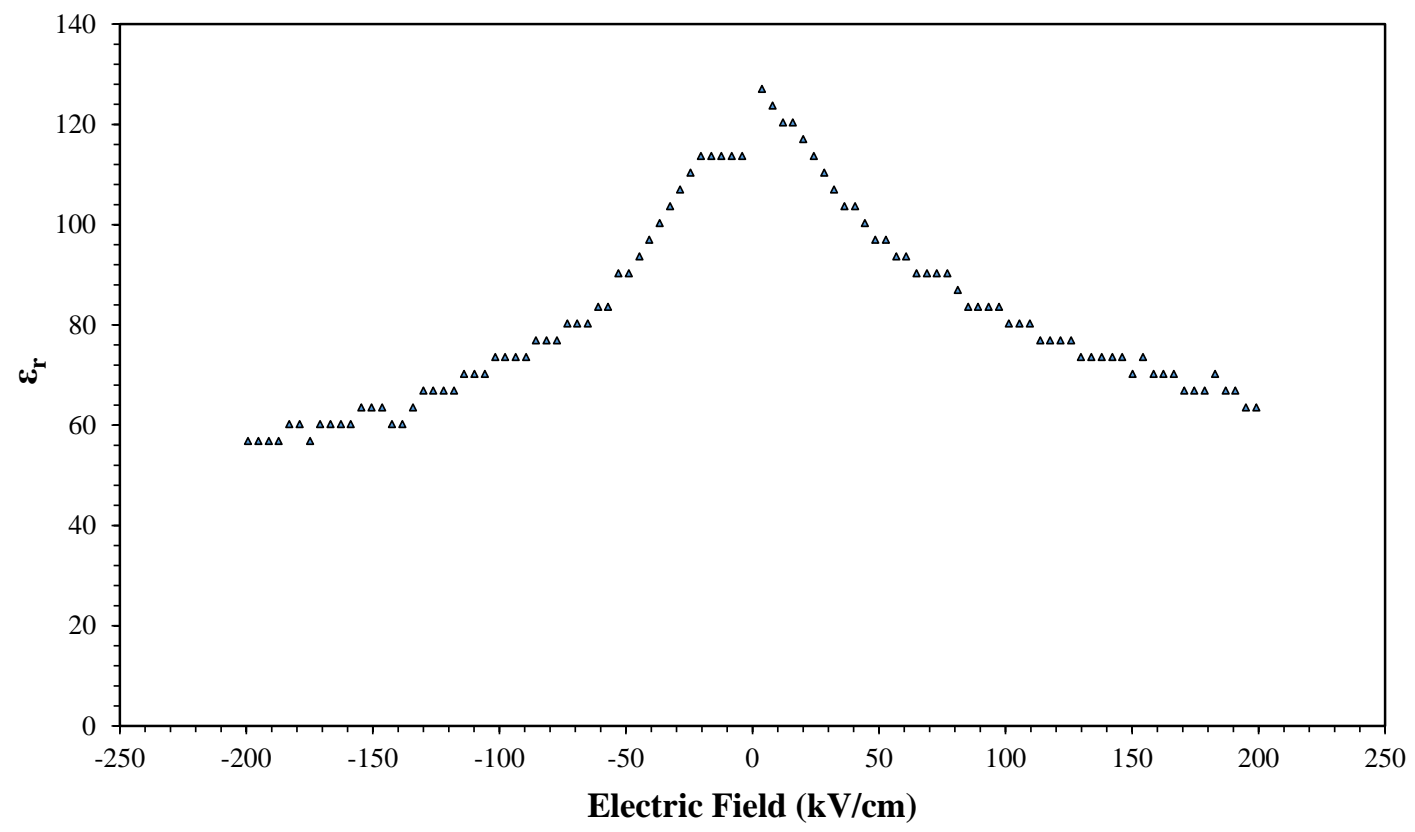

Figure 3.6 Permittivity-electric field profile measured longitudinally for randomly oriented PZT between interdigitated electrodes (IDEs) with $2 \mu \mathrm{m}$ gap. The information was derived from the $\mathrm{CV}$ switch linear profile.

Table 3.3 Interdigitated electrodes design used for ferroelectric characterization of the randomly oriented PZT film and area estimation.

\begin{tabular}{ccccccc}
\hline Design \# & a [um] & b [um] & Overlap & Number of & Film Thickness & Area \\
& & & pairs & & {$[\mathbf{n m}]$} & {$\left[\mathbf{c m}^{2}\right]$} \\
\hline 1B & 2 & 2 & 30 & 12 & 300 & 0.00000216 \\
\hline 73B & 2 & 2 & 90 & 12 & 300 & 0.00000648 \\
\hline 151A & 2 & 2 & 160 & 25 & 300 & 0.000024 \\
\hline
\end{tabular}

\section{CONCLUSIONS}

The characterization of the PZT films deposited over the two multilayer structures was performed. $\mathrm{Si}-\mathrm{SiO}_{2}-\mathrm{TiO}_{\mathrm{x}}$ and was performed. X-ray diffraction analysis revealed the expected $\{100\}$ texturized PZT grown over the $\mathrm{Si}-\mathrm{SiO}_{2}-\mathrm{TiO}_{\mathrm{x}}-\mathrm{Pt}$ structure and the randomly oriented $\mathrm{PZT}$ grown over $\mathrm{Si}-\mathrm{SiO}_{2}-\mathrm{TiO}_{x}$. AFM images presented a grain size average of $57.67 \mathrm{~nm}$ with a standard 
deviation of $23.65 \mathrm{~nm}$ and roughness of $2.064 \mathrm{~nm}$ for textured PZT, which agree with literature results, and a grain size average was $45.82 \mathrm{~nm}$ with a standard deviation of $23.3 \mathrm{~nm}$ and a surface roughness $6.49 \mathrm{~nm}$ for randomly oriented PZT. Although the difference between the observed results was not big, the larger grain size of PZT (100) grown over $\mathrm{Si} / \mathrm{SiO}_{2} / \mathrm{TiO}_{x} / \mathrm{Pt}$ (111) can be connected to a lower nucleation density and larger activation energy for the nucleation in comparison to PZT grown over $\mathrm{Si} / \mathrm{SiO}_{2} / \mathrm{TiO}_{\mathrm{x}}$. An analysis of the surface free energy (SFE) at the center of the PZT film and film edges was completed. It was found for the textured PZT, a variation of $\sim 13 \%$ which connects to the stress existing over the surface, would help to promote the delamination observed in the last chapter as a way to release this energy. The P-V response measured on randomly oriented PZT longitudinally, using the interdigitated electrodes (instead of the parallel plate electrodes typically used for texturized PZT) reflected a characteristic hysteresis loop of the ferroelectric materials. These results confirm the ability to use the $\mathrm{Si} / \mathrm{SiO}_{2} / \mathrm{TiO}_{\mathrm{x}} / \mathrm{PZT}$ as the piezoelectric substrate for the SAW device. 


\section{CHAPTER 4 SAW DEVICE DESIGN}

\subsection{INTRODUCTION}

The design of a surface acoustic (SAW) wave device is defined by the material selection section and the parametric determination of the IDTs. In the previous chapters the work made on the material selection of the device which consisted on a multilayered $\mathrm{Si} / \mathrm{SiO}_{2} / \mathrm{TiO}_{\mathrm{x}}$ structure to which $300 \mathrm{~nm}$ of randomly oriented PZT were deposited on top was presented. The parametric determination of the interdigitated electrodes (IDTs) is the subsequent required step in the SAW device design.

Figure 4.1 presents the basic design of an interdigitated transducer. The parameters that define it are: the finger width (a), the finger spacing (b), the pitch (p), the aperture, the finger overlap, the delay line and the number of fingers $(\mathrm{N})$. When a sinusoidal electrical signal is applied to the first interdigitated transducer, the electrodes will alternate polarity creating alternating electric fields. Due to the piezoelectric effect the material in between the electrodes will suffer tensile and compressive strain cyclically that will give origin to the surface acoustic wave. The characteristic wave velocity $\left(v_{0}\right)$, frequency $\left(f_{0}.\right)$ and wavelength $(\lambda)$ are related by equation 4.1 .

$$
v_{0}=f_{0 . \lambda}
$$




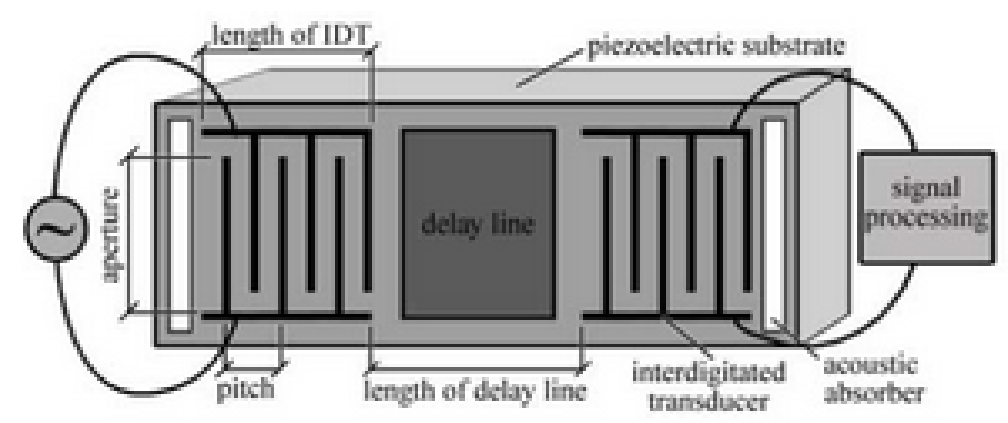

Figure 4.1 Surface Acoustic Wave device diagram. [9]

The Rayleigh wave is the first surface acoustic mode that can propagate in a given material. This wave is a mixture of a longitudinal wave and a shear wave with an energy profile that varies by depth proportionally to $e^{-2 \pi \frac{y}{\lambda}}[27,27]$. The characteristic frequency fo of the device to the propagation velocity and the device pitch is related by equation 4.2 .

$$
f_{0}=\frac{v_{0}}{p}
$$

Another important parameter is the bandwidth (BW) of the device that describes the range of frequency distribution of the wave generated by the input IDT. By minimizing the BW, the amplitude of the characteristic frequency relative to the nearby frequencies is increased. Equation 4.3 describes the relation between the $\mathrm{BW}, f_{0}$ and $N$.

$$
B W=2 \frac{f_{0}}{N}
$$

When a SAW device is used as a sensor by means of a loading mechanism produced in the delay line when specific species are absorbed or bind in the delay line, a sensitivity factor $(S)$ for this sensor can be described. $S$ is related to a material constant $\left(c_{m}\right)$ and to the operating frequency by equation 4.4. It is clear that the higher the operational frequency of the SAW device when used as a sensor, the more sensitive it becomes [27].

$$
S=C_{m} f_{o p}
$$


From these equations it is noticeable that the wave propagation velocity works in conjunction with the IDTs design parameters to determine the SAW response.

\subsection{PROPAGATION WAVE VELOCITY MODELING}

The propagation velocity of the surface acoustic wave is an important parameter to estimate before the fabrication stage of a SAW sensor, because it has direct implications on the characteristic synchronous frequency of the device, as is well-known from the fundamental relationship: $f_{0}=v /$ $\lambda_{0}$. Working with a multi-layered structure is different than working with a bulk material, since the propagation velocity will not be necessarily dependent on the surface material only. The ratio of film thickness to the SAW wavelength is important, since there is a direct impact on the contribution of the different layers to this velocity depending on this ratio. The estimation of the propagation surface wave velocity was completed using a method based on an electromechanical equivalent model of the multi-layer structured SAW sensor [28]. This model allows for the calculation of the propagation wave acoustic velocity in cases in which the thickness of the upper layer is much smaller than the signal wavelength. Since we are limited by the maximum thickness of the PZT film (cracking and compositional gradients are difficult to control with increasing thickness) [29] and also limited with the minimum values of IDTs gap we can work with (due to minimum resolution of photo-mask; the wavelength is proportional to the IDTs finger pitch $(\lambda=4 a))[30]$, this model best fits the design requirements since these conditions allow us to move in a $k h$ range of 0 to 0.5 (being $k=2 \pi / \lambda$ the wave number and $h$ the PZT film thickness).

Equation (4.5) expresses the velocity from the theorem of variation [20]. In the equation $v_{b}$ corresponds to the propagation velocity of the basic layer (silicon in our model) when there are no 
other films over it; $Z_{u}, Z_{d}$ and $Z_{b}$ correspond to the characteristic impedance of the upper layer the middle layer and the basic layer respectively. In our case the middle layer is a composite of $\mathrm{SiO}_{2}$ and $\mathrm{TiO}_{2}$ for the $\mathrm{Si} / \mathrm{SiO}_{2} / \mathrm{TiO}_{2} / \mathrm{PZT}$ structure and $\mathrm{SiO}_{2} \& \mathrm{TiO}_{2} \&$ Pt for $\mathrm{Si}_{/} \mathrm{SiO}_{2} / \mathrm{TiO}_{2} / \mathrm{Pt} / \mathrm{PZT}$ structure. The upper layer corresponds to PZT film.

$$
v=\frac{v_{b}}{1+\left(\left(Z_{u}+Z_{d}\right) / Z_{b}\right)}
$$

In table 4.1, the parameters used for the model are presented; the thicknesses correspond to the ones that were finally chosen. It should be noticed that the thicknesses used were the ones measured from a successfully fabricated multilayered system, this is, after being able to obtain the film PZT with the correct phase without cracks or pores. The thicknesses were measured using a profilometer step-by-step.

Table 4.1 Material properties (density, propagation velocity, thickness) used for model estimation.

\begin{tabular}{cccc}
\hline Material & $\begin{array}{c}\text { Density } \\
\left(\mathbf{g r} / \mathbf{c m}^{3}\right)\end{array}$ & $\begin{array}{c}\text { Thickness } \\
(\boldsymbol{\mu m})\end{array}$ & $\begin{array}{c}\text { Propagation wave } \\
\text { velocity }(\mathbf{m} / \mathbf{s})\end{array}$ \\
\hline $\mathbf{S i}$ & $2.329[28]$ & 300 & $5100[31]$ \\
\hline $\mathbf{S i O}_{2}$ & $2.2[28]$ & 1.2 & - \\
\hline $\mathbf{T i O}_{2}$ & $4.23[32]$ & 0.03 & - \\
\hline $\mathbf{P Z T}$ & $7.6[12]$ & 0.3 & -
\end{tabular}

In figure 4.1 the dispersion curve: velocity-khPZT estimation is presented ( $h_{P Z T}$ is the film thickness of PZT). A way to analyze the curve is by choosing a determined film thickness and a wavenumber, then the abscissa can be defined. The propagation wave velocity is read on the ordinate. Having the propagating wave velocity and the wavelength, the theoretical characteristic frequency of the SAW device can be estimated. In figure 4.2 the $\lambda v s$ Velocity and $\lambda v s$ Characteristic Frequency 
derived from the velocity estimation and considering that the $h_{P Z T}=300 \mathrm{~nm}$ is presented. It is interesting to notice how the velocity tend to plateau at the propagation velocity of silicon (100) with the increase of the wavelength, this shows the influence of the wafer when $\lambda$ is much bigger than the thickness of the film.

An important thing to mention is that we realize that this model simplifies the surface wave propagation velocity in a multilayer structure but considering the lack of information in literature for this particular structure it was necessary to make this study to design the different IDTs and estimate the frequency response ranges of the devices.

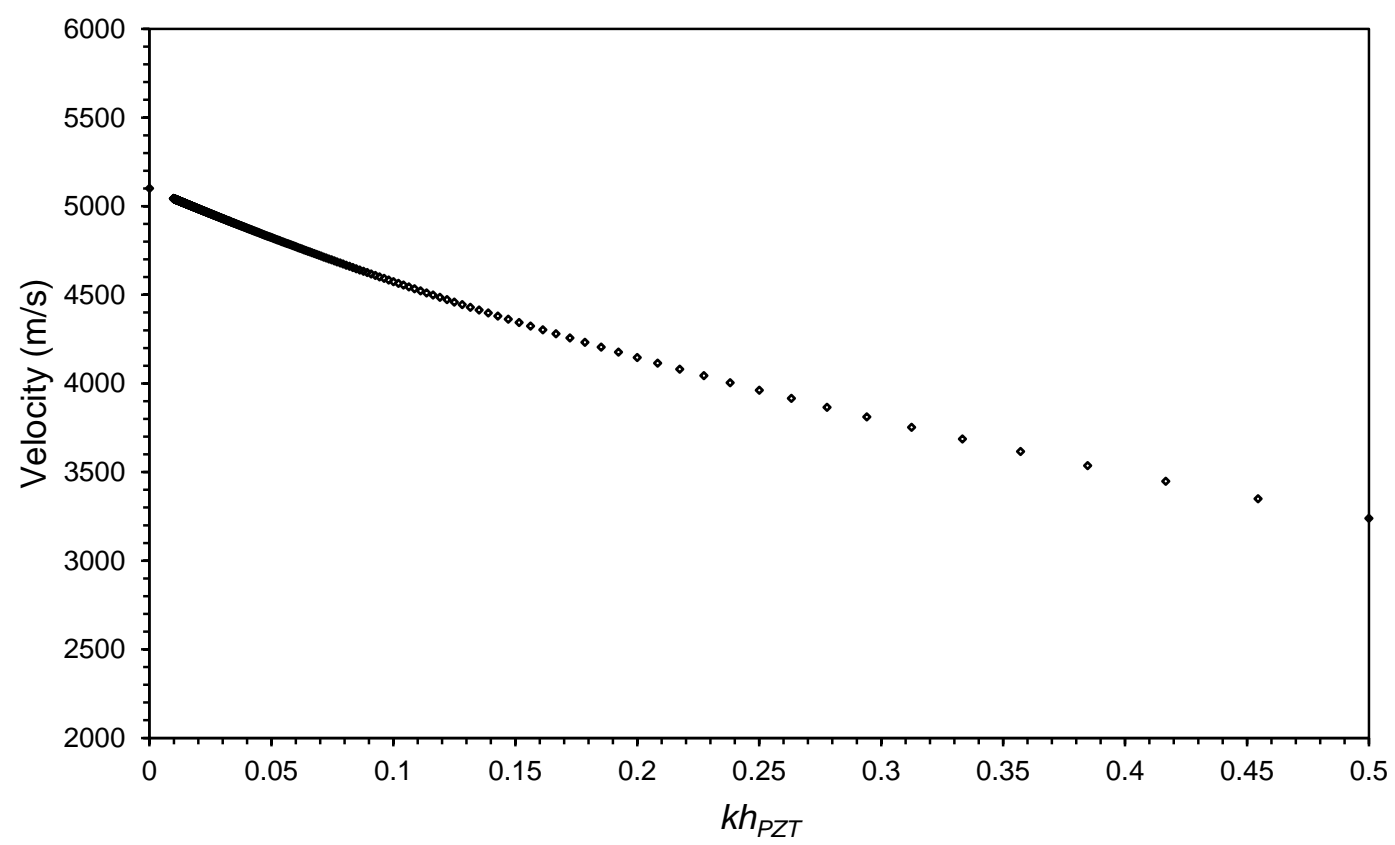

Figure 4.1 kh $\mathrm{PZT}_{\text {vs }}$ Velocity estimation made for $\mathrm{Si}(100) / \mathrm{SiO}_{2} / \mathrm{TiO}_{2} / \mathrm{PZT}$ using an electromechanical equivalent model 


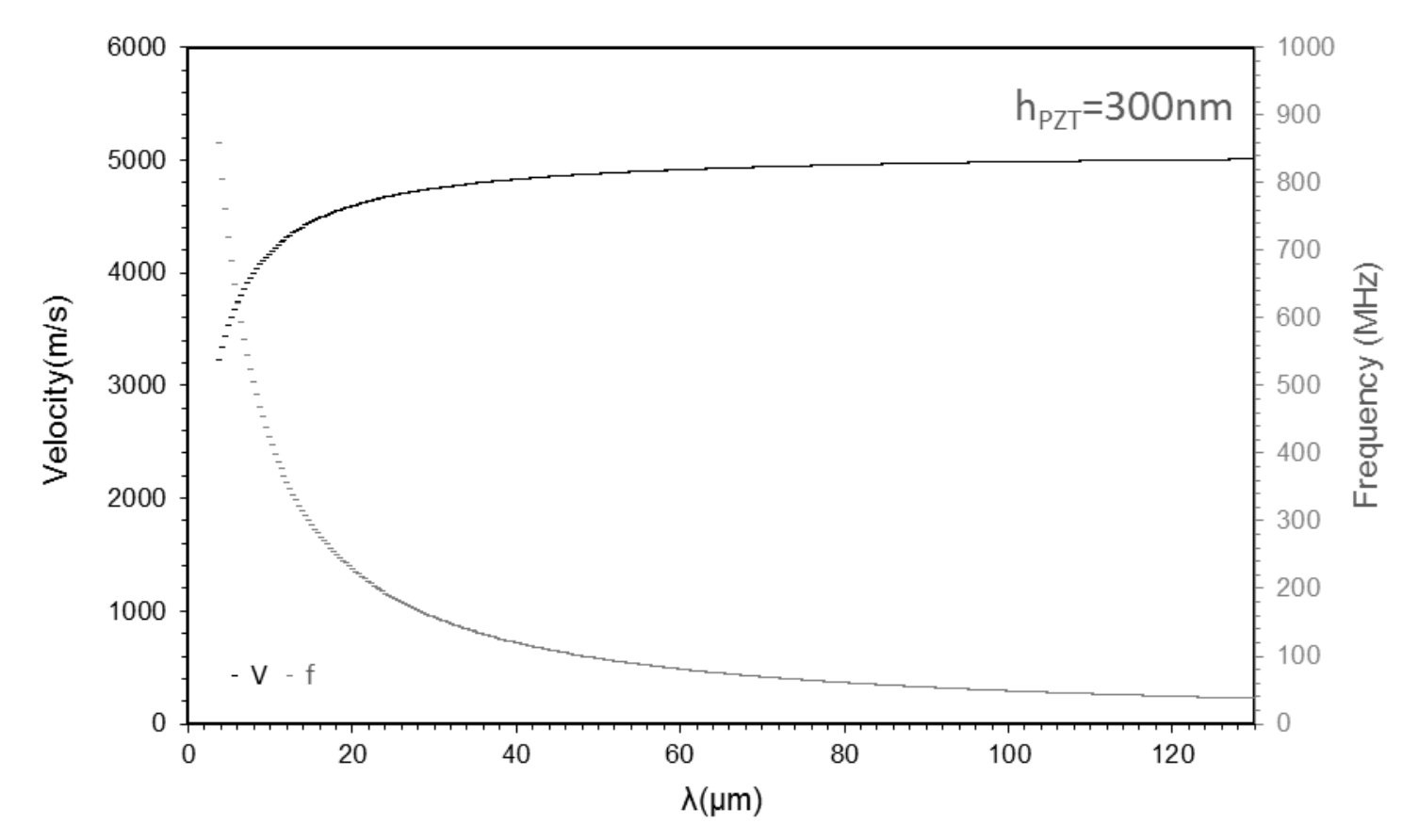

Figure 4.2 $\lambda$ vs Velocity and $\lambda$ vs Characteristic Frequency derived from the velocity estimation made for $\mathrm{Si}(100) / \mathrm{SiO} 2 / \mathrm{TiO} 2 / \mathrm{PZT}$ using an electromechanical equivalent model and considering that the $\mathrm{hPZT}=300 \mathrm{~nm}$.

\subsection{INTERDIGITATED ELECTRODES DESIGN}

Different masks for photolithography were designed and used during the present work. As it was mentioned in the last section, the idea was to have a broad spectrum of options to work with by considering the propagation velocity calculated in the previous section in conjunction with the operational frequency, band width and sensitivity as the reference point. The different designs used in this work are summarized in the table 4.2. One important aspect to be mentioned is that some of the IDT designs had ground electrode geometries surrounding the IDTs, as well as, the IDTs and the delay line. This was done in order to study how the performance of the device could improve by helping to eliminate sources of error as electromagnetic feedthrough (EF), as well as, interference due to the interaction of the created waves with the surrounding designs. 
Table 4.2 Parameters of the interdigitated electrodes (IDTs) designed and used for the

SAW device fabrication and testing.

\begin{tabular}{|c|c|c|c|c|c|c|}
\hline $\begin{array}{c}\text { Design } \\
\text { description }\end{array}$ & $\begin{array}{c}\text { Finger } \\
\text { width } \\
\text { [um] }\end{array}$ & $\begin{array}{c}\text { Finger } \\
\text { Spacing } \\
\text { [um] }\end{array}$ & $\begin{array}{c}\text { Overlap } \\
\text { [um] }\end{array}$ & Number of pairs & $\begin{array}{c}\text { Delay } \\
\text { line } \\
{[\# \lambda]}\end{array}$ & $\begin{array}{c}\text { GEG } \\
\text { (Yes/No/Both) }\end{array}$ \\
\hline $\mathbf{1 A}$ & 2 & 2 & 30 & 12 & $18 \frac{1}{4} \lambda$ & Both \\
\hline $2 A$ & 2 & 2 & 30 & 12 & $18 \frac{1}{4} \lambda$ & Both \\
\hline $\mathbf{3 A}$ & 2 & 2 & 30 & 12 & $18 \frac{1}{4} \lambda$ & Both \\
\hline $4 \mathrm{~A}$ & 2 & 2 & 30 & 12 & $18 \frac{1}{4} \lambda$ & Both \\
\hline $\mathbf{5 A}$ & 2 & 2 & 30 & 12 & $18 \frac{1}{4} \lambda$ & Both \\
\hline $7 \mathrm{~A}$ & 2 & 2 & 30 & 25 & $25 \frac{1}{4} \lambda$ & Both \\
\hline 26A & 2 & 2 & 48 & 12 & $18 \frac{1}{4} \lambda$ & Both \\
\hline 31A & 2 & 2 & 48 & 25 & $25 \frac{1}{4} \lambda$ & Both \\
\hline 32A & 2 & 2 & 48 & 25 & $25 \frac{1}{4} \lambda$ & Both \\
\hline 73A & 2 & 2 & 90 & 12 & $18 \frac{1}{4} \lambda$ & Both \\
\hline 103A & 2 & 2 & 112 & 25 & $25 \frac{1}{4} \lambda$ & Both \\
\hline 115A & 6 & 6 & 112 & 25 & $5 \frac{1}{4} \lambda$ & Both \\
\hline 151A & 2 & 2 & 160 & 25 & $25 \frac{1}{4} \lambda$ & Both \\
\hline G & 8 & 8 & 1280 & 25 & $3 \lambda$ & Yes \\
\hline 1 & 20 & 20 & $40 \lambda$ & 25 & $40 \frac{1}{4} \lambda$ & No \\
\hline 2 & 50 & 50 & $50 \lambda$ & 30 & $50 \frac{1}{4} \lambda$ & No \\
\hline 3 & 75 & 75 & $20 \lambda$ & 30 & $20 \frac{1}{4} \lambda$ & No \\
\hline 4 & 25 & 25 & $20 \lambda$ & 20 & $20 \frac{1}{4} \lambda$ & No \\
\hline 5 & 20 & 20 & $20 \lambda$ & 25 & $54 \frac{1}{4} \lambda$ & No \\
\hline 6 & 10 & 10 & $50 \lambda$ & 20 & $10 \frac{1}{4} \lambda$ & No \\
\hline 7 & 25 & 25 & $30 \lambda$ & 20 & $30 \frac{1}{4} \lambda$ & No \\
\hline 8 & 25 & 25 & $30 \lambda$ & 13 & $30 \frac{1}{4} \lambda$ & No \\
\hline
\end{tabular}




\section{CONCLUSIONS}

The process followed for the design of the interdigitated transducers that were used to fabricate the sensors was presented. Due to the influence in the SAW parameters that the propagating wave velocity demonstrates, an electromechanical model was used to predict the propagating velocity in the $\mathrm{Si} / \mathrm{SiO}_{2} / \mathrm{TiO}_{\times} / \mathrm{PZT}$ multilayer structure. These results were used for reference to design different IDTs that covered a high spectrum of wavelength, from $8 \mu \mathrm{m}$ to $300 \mu \mathrm{m}$. Another feature that was used for response comparison purposes was the ground electrode geometries surrounding the IDTs. Photolithography masks were used with these designs and SAW devices were built following the procedure presented in Chapter 2 . 


\section{CHAPTER 5 SAW DEVICE RESPONSE}

\subsection{INTRODUCTION}

The electro-acoustic measurements for the characterization of the SAW devices made during the presented work evolved with time. Originally a N9913A FieldFox Handheld RF Combination Analyzer, $4 \mathrm{GHz}$ (VNA, Agilent Technologies Inc., CA, USA) connected to a high frequency widthband balun transformer $5 \mathrm{MHz}-1.2 \mathrm{GHz}$, model NH16447 (North Hill.tm signal processing, NY, USA) was used for this purpose. The SAW devices were wire bonded to a board and the board attached to pins that connected to coaxial cables and then to the baluns and N.A. This method of wiring produced a very low signal-noise ratio (SNR). The next setup included a probe station that connected the IDTs to the Baluns-VNA. Although this method eliminated many of the connections previously described, and by this reduced sources of error, a low SNR still existed. These results motivated the change of the entire characterization system that was then the finally used. An Agilent E8362B Vector network analyzer that allowed response study up to $40 \mathrm{GHz}$ was used inside a faraday cage in order to eliminate outside interference. A Cascade Microtech ACP40GSG-150 probe connecting the SAW devices to the VNA through Cascade Microtech 101-162B

$40 \mathrm{GHz}$ cables was used. Calibrations before the measurements was done using a Cascade Microtech 101-190 impedance standard substrate (ISS) to minimize the losses in the test set up. This new system allowed the measurement of $\left|\mathrm{S}_{21}\right|$ response of the SAW devices under test. 


\subsection{FREQUENCY RESPONSE OF SAW DEVICES BASED ON RANDOMLY ORIENTED PZT THIN FILM}

Randomly oriented PZT film was deposited by sol-gel technique over a multilayered structure of $\mathrm{Si} / \mathrm{SiO}_{2} / \mathrm{TiO}_{\mathrm{x}}$ as it is described in chapter 2 . SAW devices were fabricated by sputtering various IDTs designs over the $300 \mathrm{~nm}$ thick PZT film.

Figure 5.1 corresponds to the $\left|\mathrm{S}_{21}\right|$ mode device responses obtained for the same IDTs design "G" which produces a wavelength $\lambda_{0}=32 \mu \mathrm{m}$ and has a $k h_{P Z T}=0.06$. Five responses were plotted: $\# \mathrm{C} 2$, \#C4, \#C6, \#D4 and \#D6. The letters 'C' and ' $\mathrm{D}$ ' identify two different substrates with the same structure that were fabricated for comparison of repetitive purposes. In all the responses, we can see a similar pattern in which a resonance peak is observed at $184.7 \mathrm{MHz}$ with a standard deviation of 0.6 MHz. The loss peaks for the designs in substrates ' $\mathrm{C}$ ' correspond to $-62 \mathrm{~dB}$ whereas for substrate ' $\mathrm{D}$ ' correspond to $-66 \mathrm{~dB}$. We identified this peak as the one corresponding to the Rayleigh mode. The propagation velocity derived from this values correspond to $\sim 5850 \mathrm{~m} / \mathrm{s}$. This results differs from the approximation made in Chapter $4(\sim 5000 \mathrm{~m} / \mathrm{s})$, which is due to the fact that the used model presents an analysis of the propagation velocity in multilayer structure that does not take into account characteristics such as defects, propagation velocities middle layers and material stiffness, among others, that will influence the resulting propagation velocity.

An interesting outcome was that when the device response was measured again after interchanging the cable connections or the input and output IDTs as well, the peak corresponding to the Rayleigh mode was maintained, but the intensity of this peak corresponding to it, and relative to the peaks next to it could change. These low SNR surrounding the characteristic frequency is attributed to 
inter-IDT reflections and electromagnetic feedthrough (EF) which create a noticeable effect on the response.

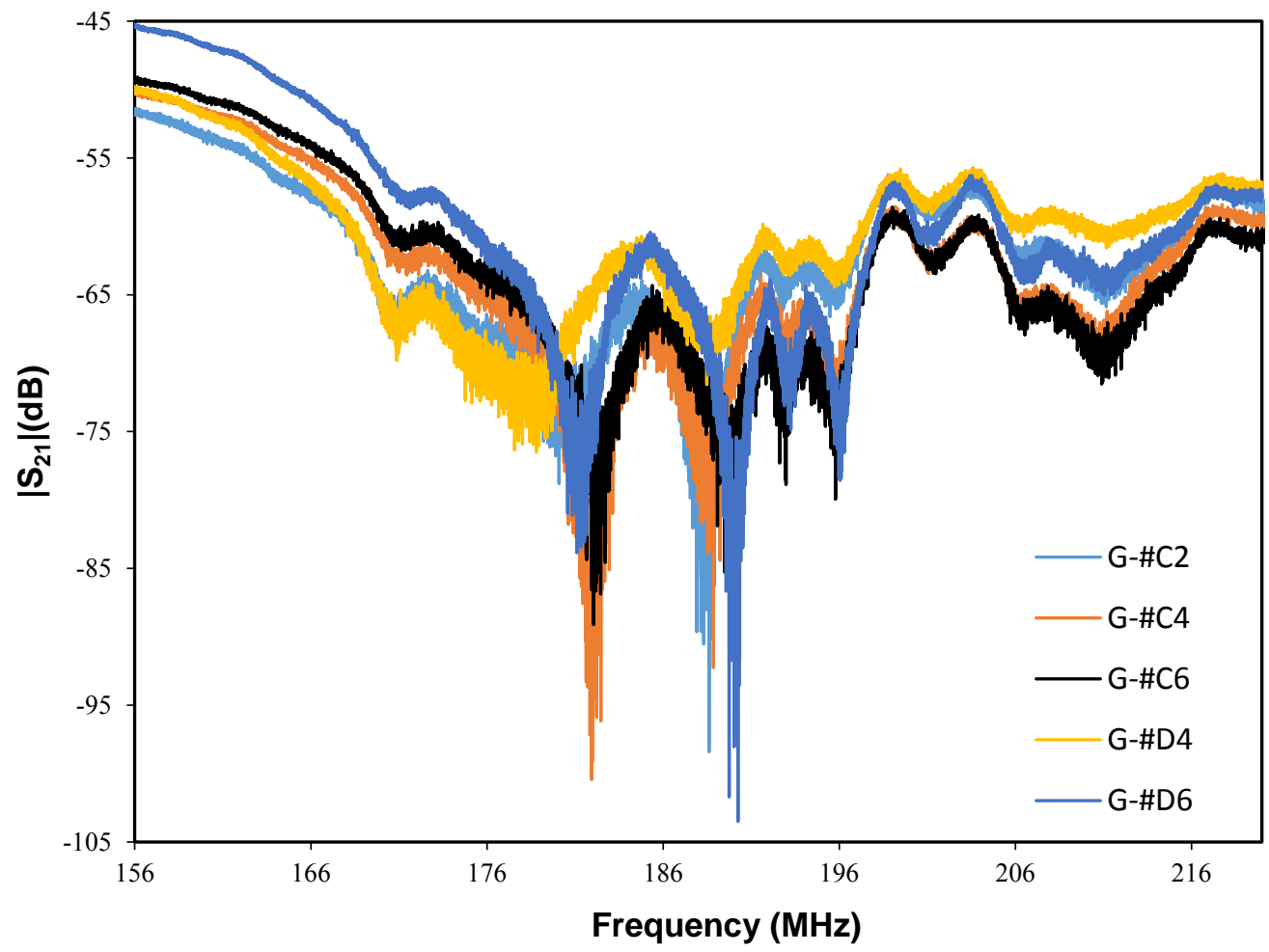

Figure 5.1 Frequency response of SAW devices based on a multilayered structure of $\mathrm{Si} / \mathrm{SiO}_{2} / \mathrm{TiO}_{\mathrm{x}} / \mathrm{PZT}(300 \mathrm{~nm})$ with IDTs corresponding to the design ' $\mathrm{G}$ ', wavelength $\lambda_{0}=32 \mu \mathrm{m}$. ' $\mathrm{C}$ ' and ' $\mathrm{D}$ ' are two different substrates to which the saw sensors were fabricated following the same procedure.

\subsection{NON RAYLEIGH SAW MODES}

Rayleigh mode is the first surface acoustic wave mode ( $0^{\text {th }}$ order mode) that propagates in a given material. The $1^{\text {st }}$ order mode it is named Sezawa mode wave. The next modes of propagation are referred as $2^{\text {nd }}, 3^{\text {rd }}, 4^{\text {th }}$ and so on. These higher frequency modes existence is highly dependent on the crystal axis of the substrate in which they are propagating. The acoustic velocity in these higher modes could be theoretically estimated using perturbation theory [33]. 
In figure 5.2, the wideband frequency $\left|\mathrm{S}_{21}\right|$ mode device responses obtained for different designs of IDTs is presented. From table 5.1, all these ground electrode geometries used have in common a width and spacing of $2 \mu \mathrm{m}$ with $\lambda_{0}=8 \mu \mathrm{m}$ and $k h_{P Z I}=0.23$. As it was mentioned in the last chapter, a multilayered structure makes it difficult to predict the theoretical propagation velocity, particularly when $k h_{P Z T}<2 \pi$, then to estimate the particular frequency at which the $0^{\text {th }}$ mode is propagating, it is difficult to do with high accuracy. From $600 \mathrm{MHz}$ up to $1 \mathrm{GHz}$, we observed a response characterized by a low signal-noise ratio which does not allow determination of the operational frequency response in Rayleigh mode. An interesting result is that at $\sim 1.45 \mathrm{GHz}$, we observed a well define resonance peak which it is believed to correspond to a Sezawa mode wave. The interest characteristic of this found propagation mode is that it would allow the selection of a high a frequency in the GHz range when using the device for sensing purposes which would increase the sensitivity of the sensor.

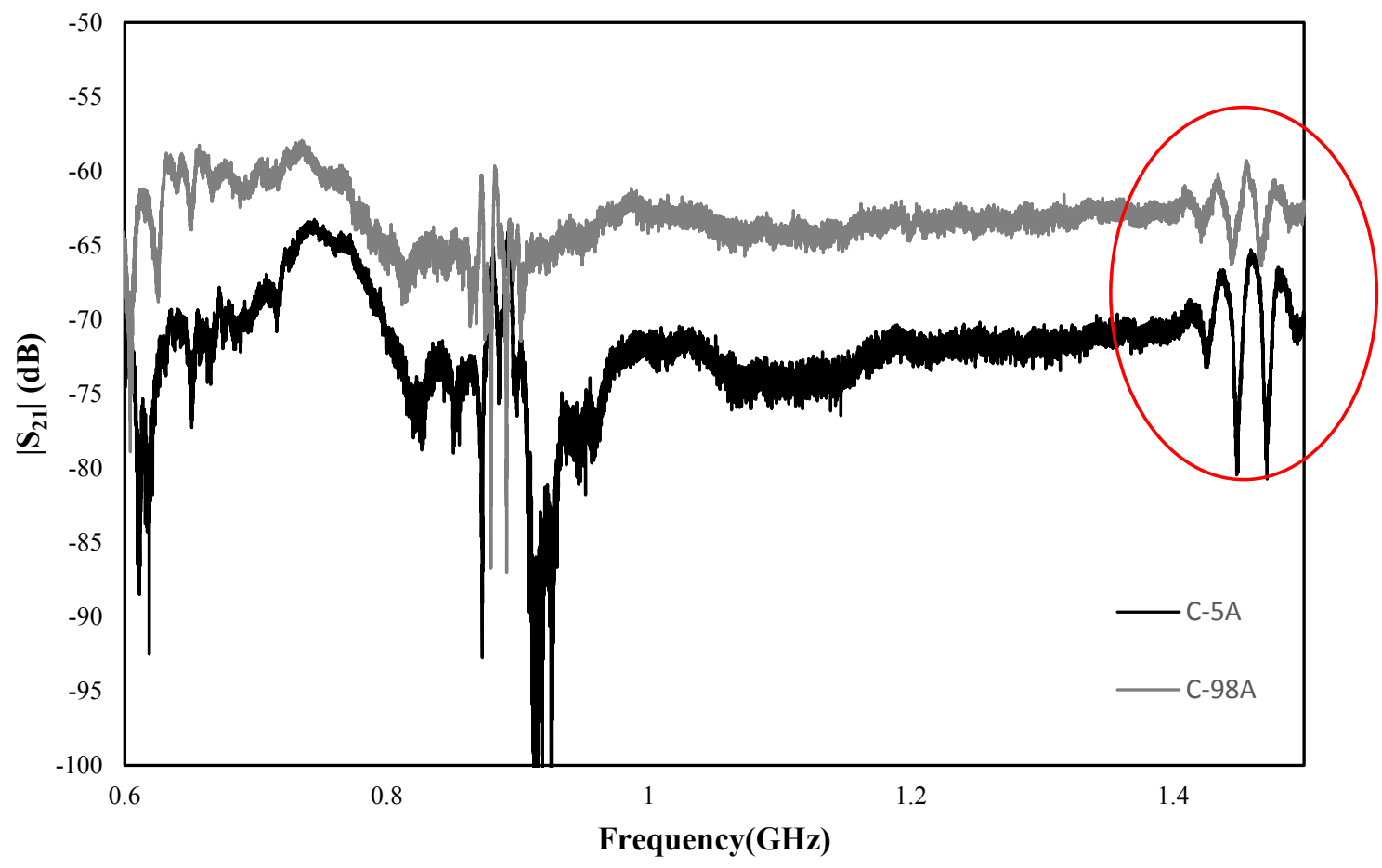


Figure 5.2 Frequency response of SAW devices based on a multilayered structure of $\mathrm{Si} / \mathrm{SiO}_{2} / \mathrm{TiO}_{\mathrm{x}} / / \mathrm{PZT}(300 \mathrm{~nm})$ with IDTs corresponding to the design $5 \mathrm{~A}$ and $98 \mathrm{~A}$, all of them with a wavelength $\lambda_{0}=8 \mu \mathrm{m}$.

These results were observed in different fabricated substrates of $\mathrm{Si} / \mathrm{SiO}_{2} / \mathrm{TiO}_{\mathrm{x}} / / \mathrm{PZT}(300 \mathrm{~nm})$ with different IDTs designs that had in common a wavelength of $8 \mu \mathrm{m}$ and a ground electrode geometries. A resonance peak at $\sim 1.45 \mathrm{GHz}$ was observed in all these cases studied and the response would not vary in time nor when cables or input and output IDTs where interchanged.

Table 5.1 Interdigitated electrodes (IDTs) parameters.

\begin{tabular}{cccccc}
\hline Design \# & $\mathbf{a ( u m )}$ & $\mathbf{b}(\mathbf{u m})$ & Overlap(um) & Number of pairs & Delay line (um) \\
\hline $\mathbf{5 A}$ & 2 & 2 & 30 & 12 & 146 \\
\hline $\mathbf{9 8 A}$ & 2 & 2 & 112 & 25 & 202 \\
\hline $\mathbf{G}$ & 8 & 8 & 1280 & 25 & 96 \\
\hline
\end{tabular}

\section{CONCLUSION}

The electro-acoustic responses of the fabricated SAW devices based on a randomly oriented PZT film (300 nm) with several IDTs designs were studied. An Agilent E8362B Vector network analyzer with Cascade Microtech ACP40-GSG-150 probes was used to study the $\left|\mathrm{S}_{21}\right|$ mode response of the devices. The Rayleigh mode response was observed in the different designs. It was noticed that surrounding this characteristic frequency, a relatively low signal-noise ratio existed that was attributed to electromagnetic feedthrough and inter-IDT reflections that created a noticeable effect. When the response of the devices was analyzed above the characteristic frequency, a higher mode response (Sezawa) was observed. These mode responses were very well 
defined and surrounding them the SNR was very small which make the selection of these frequencies more suitable for sensing purposes. 


\section{CHAPTER 6 CONCLUSIONS}

A micro-surface acoustic wave ( $\mu \mathrm{SAW})$ device based on a thin film PZT layer deposited by a solgel process was design, fabricated, characterized and tested.

Two composite configurations were fabricated: $\mathrm{Si}\{100\} / \mathrm{SiO}_{2} / \mathrm{TiOx} / \mathrm{PZT}$ and $\mathrm{Si}\{100\} / \mathrm{SiO} 2 / \mathrm{TiOx} / \mathrm{Pt}\{111\} / \mathrm{PZT}\{100\}$. These configuration were confirmed by XRD to lead to a randomly oriented and texturized PZT, respectively.

Challenges encountered during device fabrication included pores and cracking of the randomly oriented film which were solved by working on the sol spin coating and the rapid thermal annealing (RTA) stages. On the PZT $\{100\}$-multilayered structure a delamination was observed when scotch tape taste was performed from and up to the limits of the surface. After an EDX study of the surface was performed it was identified that the delamination was occurring between the $\mathrm{TiO}_{\mathrm{x}}-\mathrm{Pt}$ films. Different approaches to improve this adhesion included an $\mathrm{O}_{2}$ plasma etching to the $\mathrm{TiO}_{\mathrm{x}}$ surface before sputtering deposition, annealing the film after Pt deposition for thermal stress relaxation, and thermal sputtering of $\mathrm{Pt}$ to increase order. None of these processes succeeded in avoiding the delamination. An analysis of the surface free energy at the center of the PZT film and film limits was done finding a variation of $\sim 13 \%$. Although a deeper analysis of the $\mathrm{TiO}_{\mathrm{x}}-\mathrm{Pt}$ bonding needs to be done to get conclusive explanations of this behavior the SFE difference connects to the stress existing over the surface which is then released after the occurring delamination. Contrary, no 
delamination occurred on the randomly oriented PZT-based multilayered structure. Since the delamination effect limits the usage of a device based on the $\mathrm{Si} / \mathrm{SiO}_{2} / \mathrm{TiO}_{x} / \mathrm{Pt} / \mathrm{PZT}$ structure, especially when it is exposed to gas impacting longitudinally to the surface, the $\mathrm{Si}\{100\} / \mathrm{SiO}_{2} / \mathrm{TiO}_{\mathrm{x}} / \mathrm{PZT}$ structure was the one selected to use for the $\mathrm{SAW}$ device substrate.

A ferroelectric characterization of the randomly oriented PZT was done using interdigitated electrodes (IDTs) instead of the parallel plate mode electrodes (PPE) typically used with texturized PZT. The characteristic ferroelectric hysteresis loop was observed with remaining polarization of $15.743 \pm 0.1 \mu \mathrm{C} / \mathrm{cm}^{2}$ and the coercive field was $54.143 \pm 1.3 \mathrm{kV} / \mathrm{cm}$.

The propagation wave velocity for the $\mathrm{Si} / \mathrm{SiO}_{2} / \mathrm{TiO}_{\times} / \mathrm{PZT}$ multilayered structure was estimated using an electro-mechanical equivalent model before designing the different IDTs for the SAW devices. The obtained results were used as a reference to design different IDTs that covered a high spectrum of wavelength, from $8 \mu \mathrm{m}$ to $300 \mu \mathrm{m}$. Although the precision of the propagation velocity estimation was not as good as the one that could have been obtained by solving the wave equation of motion (which demands elaborate computations involving partial differential equations (PDEs)), it was useful for design purposes.

The frequency response of the SAW devices based on $\mathrm{Si}\{100\} / \mathrm{SiO}_{2} / \mathrm{TiO}_{\mathrm{x}} / \mathrm{PZT}$ structure was done with a VNA. Originally different connection configuration were used, but high SNR response was obtained with not identifiable resonance modes. The configuration based on a cascade Microtech ACP40-GSG-150 probe connecting the SAW devices to the VNA through Cascade Microtech 101-162B $40 \mathrm{GHz}$ cables and measured inside a faraday cage was the one that was finally used. 
The responses with more distinctive response and less noise were observed on the IDTs designs with ground electrode geometries. Rayleigh mode SAWs had an average insertion loss of $64 \mathrm{~dB}$ for devices with $\lambda_{0}=32 \mu \mathrm{m}$ and a resonance frequency of $184.7 \mathrm{MHz}$. It was noticed around the resonance peak a low SNR, which was attributed to inter-IDT reflections and electromagnetic feedthrough (EF), and this created a noticeable effect on the response. Non-Rayleigh mode SAWs were noticed in devices where $\lambda_{0}=8 \mu \mathrm{m}$ with a resonance frequency of $1.45 \mathrm{GHz}$ and with insertion loss around $63 \mathrm{~dB}$. These observed higher resonance modes had a small SNR around the resonance peak and were steady in time. 


\section{FUTURE WORK}

Regarding to the multilayered structure of the $\mathrm{Si} / \mathrm{SiO}_{2} / \mathrm{TiO}_{x} / \mathrm{Pt} / \mathrm{PZT}$ structure, it would be interesting to advance the study of the delamination between $\mathrm{TiO}_{\mathrm{x}}$-Pt layers. Performing microindentation would be a good way to do so. It would be interesting to work with different adhesion layers, as $\mathrm{ZrO}_{2}$ instead of $\mathrm{TiO}_{2}$, to see if the adhesion would improve.

It is desirable to study the SAW devices frequency response under different conditions of pressure and temperature, and study its effect in the Rayleigh and non-Rayleigh SAW modes. Since nonRayleigh SAW modes were steadier in time, and were produced at higher frequencies (which increase the sensitivity of the device), it would be desired to test these devices to gas leakages at the non-Rayleigh SAW mode resonance frequencies and record frequency and loss variation. To perform these tests, a cryogenic chamber connected to a high vacuum system will be required. This configuration have been settled. Since for this special testing configuration, it would not be possible to use the same set up of the Cascade ${ }^{\circledR}$ probes that was used for the characterization of the SAW device (which minimize the signal noise). The second step required would be to implement a special connection for the SAW device to the Vector Network Analyzer that would be able to minimize the signal to noise ratio. 


\section{REFERENCES}

[1] S. C. B. Mannsfeld, B. . C.-K. Tee, R. M. Stoltenberg, C. V. H.-H. Chen, S. Barman, B. . V. O. Muir, A. N. Sokolov, C. Reese and Z. Bao, "Highly sensitive flexible pressure sensors with microstructured rubber dielectric layers," Nature Materials, vol. 9, no. 10, p. 859-864, 2010.

[2] D. M. a. S. Deacon, "Manned GEO Satellite Servicing Mission Environmental Effects Measurements Study".NASA Report, NASA/CR-2012-217758. .

[3] A. A. V. (Ed.), Piezoelectric Transducers and Applications, Springer, 2008.

[4] C.-S. Lu, "Investigation of film-thickness determination by oscillating quartz resonators with large mass load," Journal of Applied Physics, vol. 43, no. 11, p. 4385, 1972.

[5] T. HOANG, "Design and realization of SAW pressure sensor using Aluminum Nitride," UNIVERSITE JOSEPH FOURIER- GRENOBLE I, 2009.

[6] T. Lederer, B. P. Stehrer, S. Bauer, B. Jakoby and W. Hilber, "Utilizing a high fundamental frequency quartz crystal resonator as a biosensor in a digital microfluidic platform," Sensors and Actuators A: Physical, vol. 172, no. 1, p. 161-168, 2011.

[7] B. Drafts, "Acoustic/Ultrasound Acoustic Wave Technology Sensors," SensorsOnLine, 2000. 
[8] J.

A. Garrido,

TUM-WSI,

pp.

http://www.wsi.tum.de/Portals/0/Media/Lectures/20082/98f31639-f453-466d-bbc2a76a95d8dead/BiosensorsBioelectronics_lecture10.pdf.

[9] J. Kirschner, "Surface Acoustic Wave Sensors (SAWS): Design for Fabrication," Microelectromechanical Systems, 2010.

[10] Y. J. L. A. F. a. A. A. María Isabel Rocha Gaso, "Love Wave Biosensors: A Review," in State of the Art in Biosensors - General Aspects, INTECH, 2013.

[11] N. Chidambaram, A. Mazzalai and P. Muralt, "Measurement of effective piezoelectric coefficients of PZT thin films for energy harvesting application with interdigitated electrodes," IEEE Transactions on Ultrasonics, Ferroelectrics and Frequency Control, vol. 59, no. 8, p. 1624-1631, 2012.

[12] J.-C. Yu and H.-Y. Lin, "Sensing liquid density using resonant flexural plate wave devices with sol-gel PZT thin films," Microsystem Technologies, vol. 14, no. 7, p. 1073-1079, 2008.

[13] S. T.-M. a. P. Muralt, "Thin Film Piezoelectrics for MEMS," Journal of Electroceramics, vol. 12, no. 1/2, pp. 7-17, 2004.

[14] R. A. Wolf, "Temperature dependence of the piezoelectric response in lead zirconate titanate films," Journal of Applied Physics, vol. 95, no. 3, p. 1397, 2004.

[15] N. Ledermann, P. Muralt, J. Baborowski, S. Gentil, K. Mukati, M. Cantoni, A. Seifert

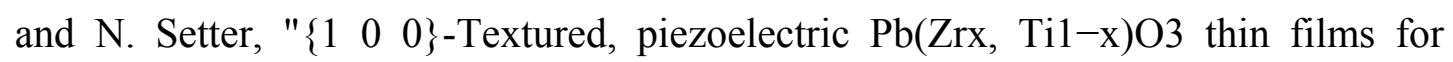
MEMS: integration, deposition and properties," Sensors and Actuators A: Physical, vol. 10, p. 162 to 170, 2003. 
[16] M. J. Haun, E. Furman, S. J. Jang and L. E. Cross, "Thermodynamic theory of the lead zirconate-titanate solid solution system, Part V: Theoretical calculations," Ferroelectrics,, vol. 99, no. 1, pp. 63-86, 1989.

[17] N. Chidambaram, A. Mazzalai, D. Balma and P. Muralt, "Comparison of Lead Zirconate Titanate Thin Films for Microelectromechanical Energy Harvester with Interdigitated and Parallel Plate Electrodes," IEEE Transactions on Ultrasonics, Ferroelectrics, and Frequency Control, vol. 60, no. 8, p. 1564-1571, 2013.

[18] R. G. P. Richard Piekarz, "Processing Method for Creating Ultra-Thin Lead Zirconate Titanate (PZT) Films Via Chemical Solution Deposition," U.S. Army Research Laboratory, ARL-TN-0338, Adelphi, MD, 2008.

[19] C. Zhu, Z. Yong, Y. Chentao and Y. Bangchao, "Applied Surface Science," Investigation the effects of the excess $\mathrm{Pb}$ content and annealing conditions on the microstructure and ferroelectric properties of PZT (52-48) films prepared by sol-gel method, vol. 253, no. 3, pp. 1500-1505, 2006.

[20] K. Mittal, Adhesion Measurement of Thin Films, Thick Films, and Bulk CoatingsASTM Standard C24, Philadelphia, Pa, 1976 640, DOI: 10.1520/STP640-EB: ASTM SPECIAL TECHNICAL PUBLICATION, 1976.

[21] W. S. Han and N. Kwangsoo, "Characterization of the Property Degradation of PZT Thin Films with Thickness," Journal of the Korean Physical Society, vol. 58, no. 4, p. $809,2011$. 
[22] F. Vasiliu, G. J. Norga, L. Fe, D. Wounters and O. Van der Biest, "The role of TiO in the perovskite nucleation and (111) orientation selection in sol-gel PZT layers," Journal of Optoelectronics and Advanced Materials, vol. 5, no. 3, pp. 777-786, 2003.

[23] "http://gwyddion.net".

[24] P. Muralt, T. Maeder, L. Sagalowicz, S. Hiboux, S. Scalese, D. Naumovic, R. G. Agostino, N. Xanthopoulos, H. J. Mathieu, L. Patthey and E. L. Bullock, "Texture control of $\mathrm{PbTiO}$ [sub 3] and $\mathrm{Pb}(\mathrm{Zr}, \mathrm{Ti}) \mathrm{O}$ [sub 3] thin films with $\mathrm{TiO}$ [sub 2] seeding," Journal of Applied Physics, vol. 83, no. 7, p. 3835, 1998.

[25] F. M. Fowkes, "Donor-acceptor interactions at interfaces," The Journal of Adhesion, vol. 4 , no. 2 , pp. $155-159,1972$.

[26] F. M. Fowkes, "Hydrophobic Surfaces," Elsevier, p. 151-163, 2012.

[27] D. S. Ballantine, R. M. White, S. J. Martin, A. J. Ricco, E. T. Zellers, G. C. Frye and H. Wohltjen, Acoustic Wave Sensors: Theory, Design, \& Physico-Chemical Applications., vol. 28, Academic press, 1996, pp. 5- 6.

[28] D. V. Tošic and M. F. Hribšek, "Modelling and wave velocity calculation of multilayer structure SAW sensors," Microelectronics International, , ., vol. 28, no. 2, pp. 3-7, 2011.

[29] F. Calame and P. Muralt, "Growth and properties of gradient free sol-gel lead zirconate titanate thin films," Applied physics letters, vol. 90, no. 6, pp. 062907-062907., 2007.

[30] "https://dev.photo-sciences.com/fasttrack".

[31] A. Ananda, "Propagation of Rayleigh Waves in Thin-Films," THE COLLEGE OF WILLIAM AND MARY, 1997. 
[32] D. R. Lide, handbook of chemistry and physics, Boca Raton: CRC, 1997.

[33] H. B. a. R. S. M. Levy, Modern acoustical techniques for the measurement of mechanical properties, Academic Press, 2001. 